Article

\title{
Prototype of a Low-Cost Compact Horticultural Chamber for Indoor Cultivation of Tropical Highland Wetland Flora
}

\author{
Mateusz Wrazidlo*(1) and Anna Bzymek \\ Department of Fundamentals of Machinery Design, Faculty of Mechanical Engineering, \\ Silesian University of Technology, 44-100 Gliwice, Poland; anna.bzymek@polsl.pl \\ * Correspondence: matwraz@gmail.com
}

Received: 4 September 2020; Accepted: 1 November 2020; Published: 3 November 2020

check for updates

\begin{abstract}
An environmental chamber is a specialistic device used for testing effects of given controlled conditions on a variety of objects. In case of plant growth chambers, the conditions are controlled usually for plant cultivation and propagation or botanical examination undertaken on living plant material. The aim of the project was to design and build a prototype of a desktop device with a control system capable of being used as a chamber supporting plant cultivation and propagation processes by the means of partial automation of environment control. The conditions controlled in the chamber are based on the environmental requirements of plant genera, such as Heliamphora, Drosera, Orectanthe, Cyrilla, Stegolepis, Maguireothamnus, or Utricularia. These plants occur naturally in the Guiana Highlands region of Venezuela, Brazil, and Guyana, especially around the upper parts of table-shaped mountain massifs called tepuis. The chamber was designed to simulate some of the peculiar natural factors and phenomena occurring in the high-tepui and surrounding mid-elevation wetland habitats, being the most significant for amateur-level plant cultivation, keeping the design as simple and low cost as possible. It was proven on the basis of the results of several tests made during the evaluation phase that the designed prototype of the chamber operates in a satisfying way, providing basic functionality matching the base assumptions.
\end{abstract}

Keywords: environmental chamber; horticultural chamber; digital control systems; sensor systems; plant cultivation; Pantepui; Guiana Highlands; tepui; horticulture

\section{Introduction}

An environmental chamber, also called a climatic or climate chamber, is a specialistic device used for testing the effects of given conditions on a variety of subjects. They are often used for reliability testing of microelectronics and other products and materials [1], as well as biological samples. It is usually designed to isolate a given item from the external environment and then replicate specific conditions that are necessary for many different purposes, depending on the object to be placed inside the chamber [2]. These conditions might be used to test the item (e.g., a material or specific mechanical component) under the exposure to amplified and accelerated damaging processes, such as erosion, low or high pressure, extreme ranges of humidity, thermal shocks, vibrations, salts and other corrosive agents, UV light, vacuum etc., being the results of changing atmospheric conditions. Sometimes, the chambers are used specifically to experiment with various physical or chemical phenomena, such as the atmospheric chemistry [3], or even to simulate the environments of other planets [4].

Depending on the application and needs, the environmental chambers can have different designs and control systems, which are necessary for keeping the desired conditions in the enclosure within the device. 
A special kind of environmental chamber are plant growth chambers, often referred to as fitotrons. These devices are commonly used for making ex situ reproducible observations in experimental plant biology research or for horticultural undertakings. The main disadvantage of professional fitotrons is that they are usually very large and expensive [5], mostly because of the fact that their range of application is very narrow, and that the group of customers interested in purchasing such devices is relatively small and limited only to research or industry professionals. Fitotrons are commonly used for very delicate and specialistic purposes like in vitro tissue culture or experimental needs; therefore, they do not find many purchasers within the group of non-professional plant growers or passionates, as for such applications they can be easily replaced with amateur solutions, such as terrariums or other homemade kits. Due to the highly specific character of this project, it is very hard, if not impossible, to find matching solutions readily available on the market. Therefore, the market research for all sub-systems and the chamber construction itself has mostly been unsuccessful.

The main target group for the designed device includes amateur and semi-professional plant enthusiasts who would like to keep species requiring specialistic conditions in an enclosure but do not possess the technical skills that would let them design and build an essential setup themselves. Practical horticultural experiences of the first author and his activity within tropical plant horticulture and conservation hobby groups brought about the conclusion that introducing such a kind of device on the market can bring possibilities for sharing and popularizing scientific and nature interests among a large number of people, especially the youth. Spreading these kinds of interests may be a crucial part of nature preservation and conservation projects in the near future, as ex situ cultivation and propagation of vulnerable plants remains one of the most effective means of ensuring the survival of the most fragile and precious species. An example of a successful introduction of an endangered species into a large-scale cultivation effort is a Bornean endemic pitcher plant from Mount Kelam in Kalimantan, Nepenthes clipeata [6]. Being critically endangered in its natural habitat due to various factors (e.g., poaching), the plant has recently been distributed among botanical gardens, in vitro nurseries, and private collectors all around the world, ensuring its survival and bringing hope for possible reintroduction in its natural habitat in the future.

\section{Materials and Methods}

The aim of this project was to design and build a prototype of a compact horticultural chamber with a simplified yet sufficient control system capable of being used as an easy-to-use low-cost device supporting plant growing and propagation processes by partially automating the process of maintaining certain environmental particulars at given levels. The envisioned target group of potential users of the chamber are mostly amateur horticulturists and tropical botany enthusiasts; therefore, the preliminary design requirements included:

- Desktop form factor of the device and its subassemblies;

- Low-cost materials;

- Intuitive operation; and

- Simplistic design.

The conditions controlled in the chamber are based on the environmental requirements of plant genera native to the Pantepui biogeographic province and its surrounding areas. This includes genera, such as Heliamphora, Drosera, Orectanthe, Cyrilla, Stegolepis, or Utricularia. These plants occur naturally in the Guiana Highlands region of Venezuela, Brazil, and Guyana, especially around the upper parts of table-shaped massifs called tepuis [7]. The chamber was designed in order to replicate natural factors and phenomena occurring in those habitats, such as:

- High levels of sunlight exposure;

- Nighttime temperature drops;

- Strong air circulation-mountain wind; and 
- High humidity levels [8-10].

The theoretical assumptions formulated for this project were based on field observations that were made during an expedition to La Gran Sabana and the massif of Akopan-tepui in Venezuela in January 2017. Akopan-tepui is a quarzite table-mountain, being part of a larger mountain massif called Chimantá (Figure 1) located within the boundaries of Canaima National Park.

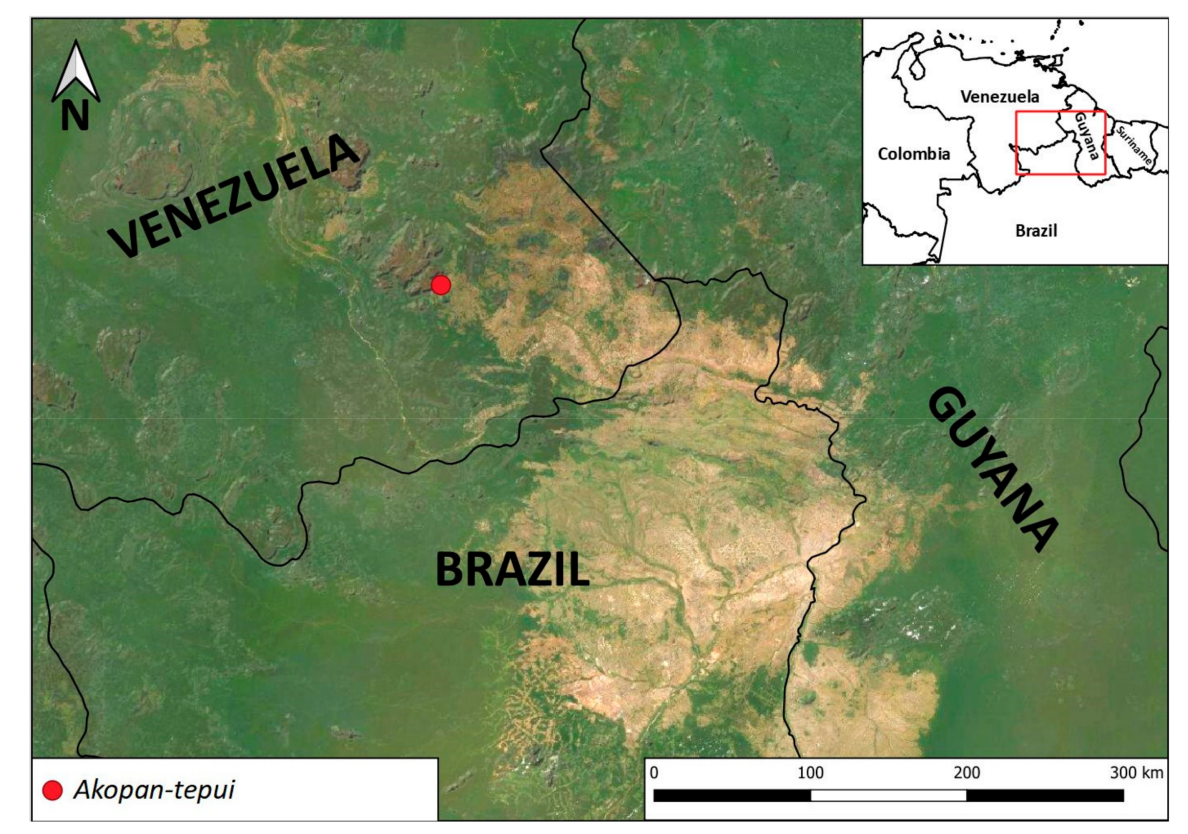

Figure 1. Map showing the location of Akopan-tepui in Venezuela (map by M. Wrazidlo, made with QGIS).

Areas of the Canaima National Park in Venezuela are very fragile spots of ancient "sky island" environments that have been preserved until modern times thanks to complex geological phenomena, which have led to the erosion of Precambrian quarzitic sandstones, forming isolated areas characterized by a high biodiversity rate and presence of endemic species (Figure 2) [11], which are, and will remain, valuable research subjects of particular significance for many fields of natural sciences throughout the upcoming decades.

The environment of the Guiana Highlands is currently being put in harm's way due to a combination of both anthropogenic and natural factors (deforestation, global warming, etc.), which leads to an advancing degradation of the natural landscape, triggering a process of gradual habitat loss, which might result in extinction of the most fragile species [12]. In total, $57 \%$ of the Pantepui area on the Cimantá Massif (Akopan-tepui included) is predicted to disappear by the end of the XXI century [13]. The creation of living plant collections was proposed as one of the possible means of ex situ species conservation [14]; therefore, a vital part of ensuring the preservation of the most valuable of them for the sake of future examination and possible re-introduction to the natural environment is developing means of recreating the desired conditions for ex situ breeding. One such mean is an environmental chamber prototype, which is the subject of this work.

The paper focuses on the process of researching the possibilities of building a simple environmental chamber capable of mimicking conditions similar to the ones occurring on the summit and mid-elevation areas of Akopan-tepui and La Gran Sabana in Venezuela. The work will cover the technical means chosen to produce a prototype of such a chamber, the designing process, with the final solution being a fully assembled operating chamber ready for hosting selected plants native to the Guiana Highlands region. 


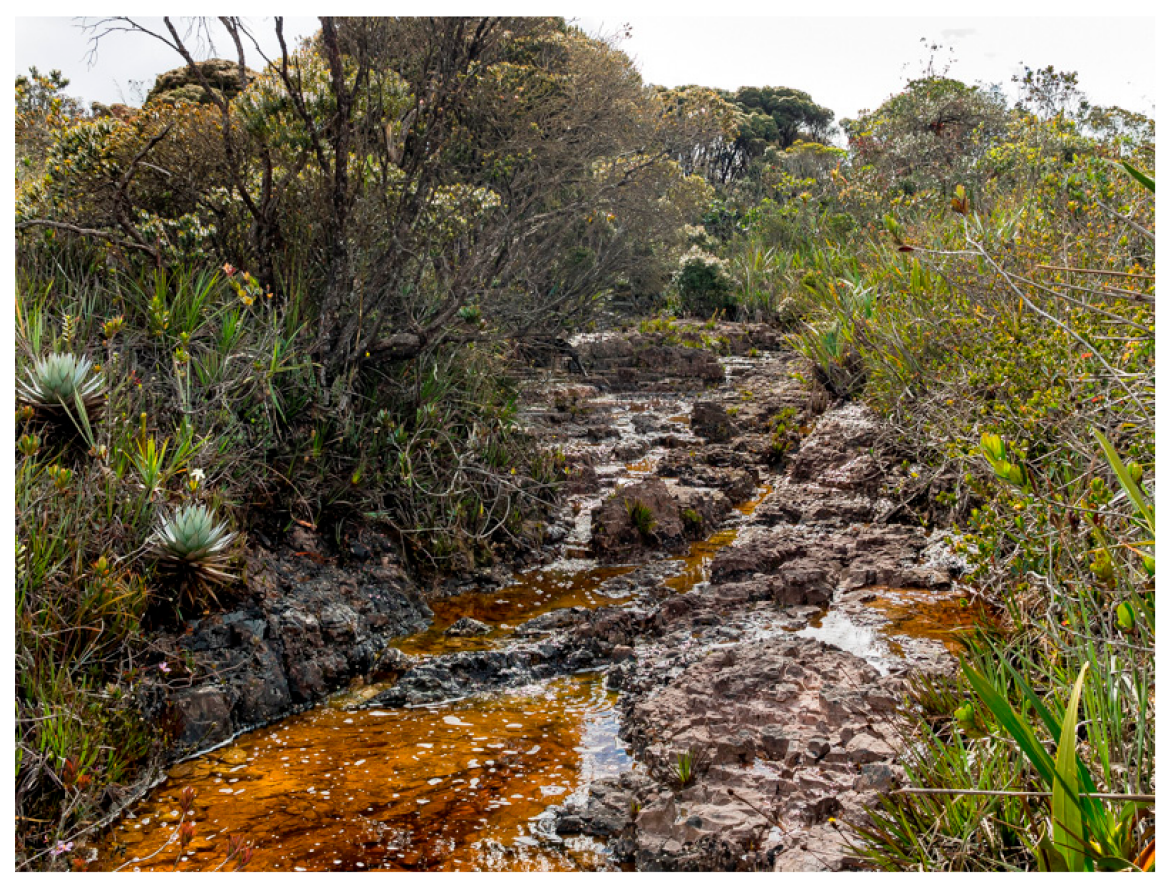

Figure 2. Wetland environment on the summit of Akopan-tepui in Venezuela.

\section{The Design Process and Assembly of the Chamber}

A thorough assessment for choosing the best and most appropriate concepts of technical solutions required to carry out the assembly of the chamber was done in the first place. Concepts of the general design, as well as of the particular sub-systems were discussed. Before starting the assembly process, a 3-D model of the device was made using Autodesk Inventor 2017 (Figure 3).

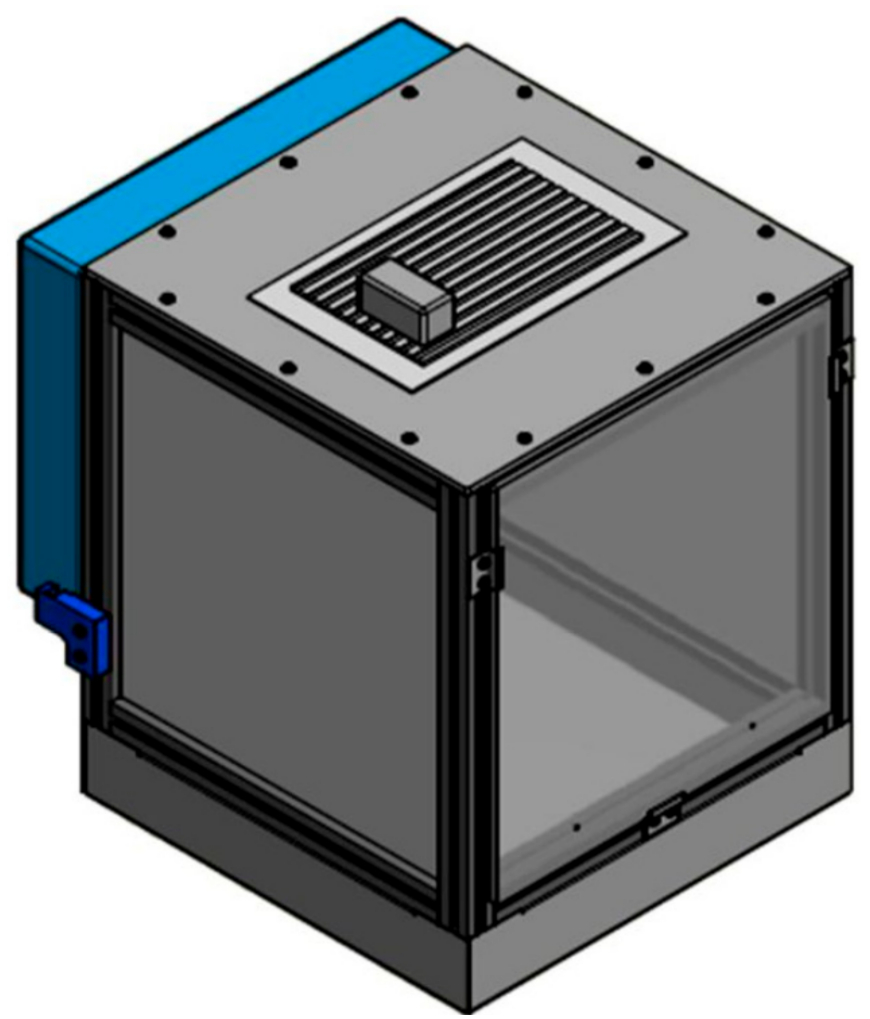

Figure 3. CAD model of the chamber made with Autodesk Inventor. 
The final solutions chosen for the project are as follows:

- Aluminum profile frame with polyurethane foam sheet walls for the base construction of the chamber, together with a watertight welded aluminum tray for the bottom (Figure 4);

- LED (light emitting diode)-based setup as a way of providing the light source;

- Sliding front cover made of transparent polycarbonate, providing insight into the chamber's interior;

- Arduino-based digital control system;

- Cooling device based on a Peltier thermoelectric effect unit;

- Plastic lattice placed at the bottom of the chamber (prevents the plants from standing in water, which might result in excessive soil moisture levels); and

- Ultrasonic fogging unit for providing adequate humidity levels.

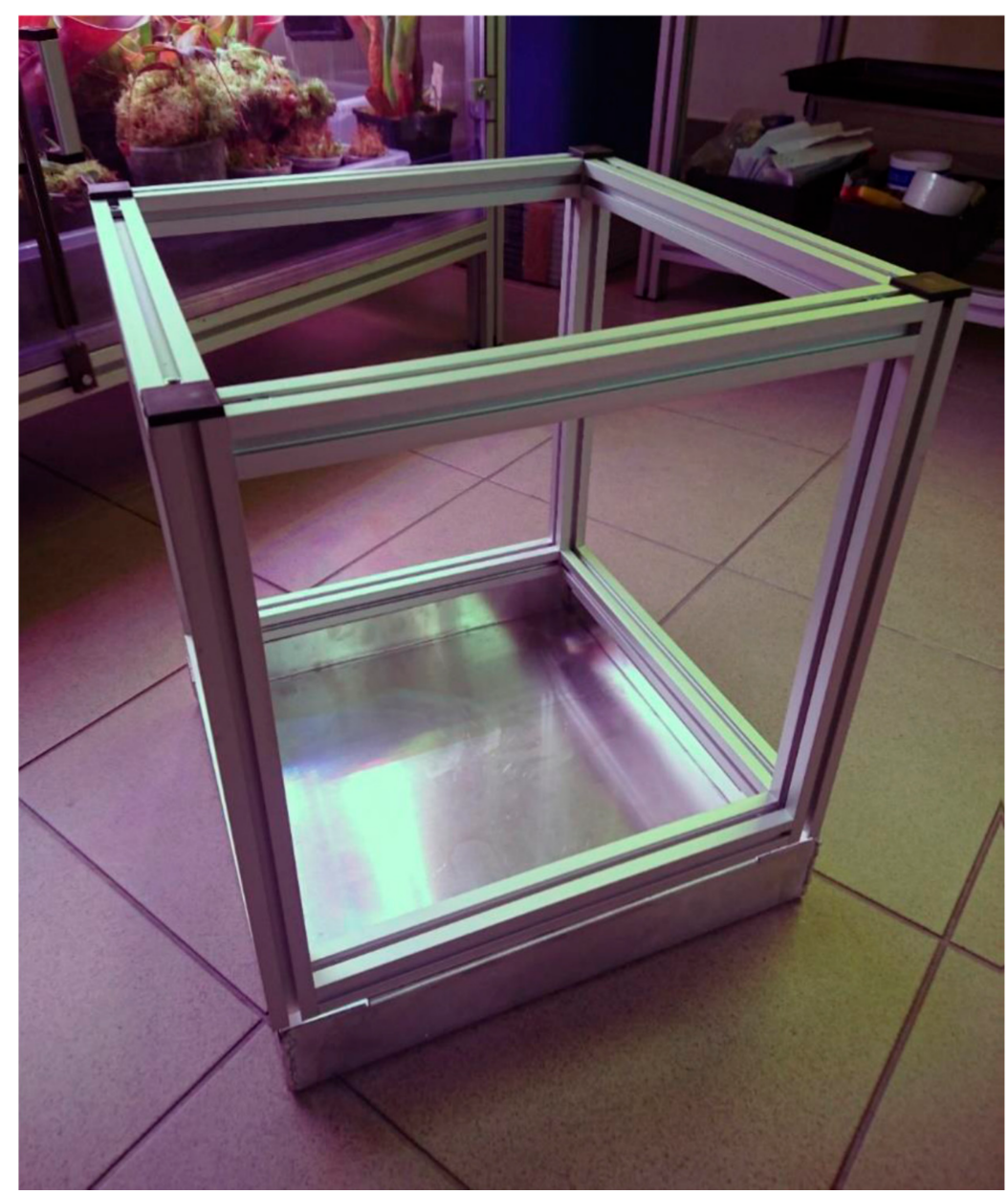

Figure 4. Aluminum profile frame of the chamber.

The materials and components chosen for the project include products that are widely available from most hardware retailers or online electronics stores. Customized parts can be easily made using simple tools (saws, drills, hot knives, etc.), or manufactured with popular FDM (Fused Deposition Modeling) 3-D printers. The electronic system is based on cheap open-source solutions, which can easily be replaced with even cheaper substitutes providing identical functionality. This approach guarantees that the final product is easy to build in most home workshops and much more affordable than professional-grade or industrial solutions available on the market.

After completing the assembly of the chamber, various basic tests were undertaken in order to confirm the watertightness of the bottom tray. Water was poured inside to check the leakages, 
and none were spotted. The thermal and moisture insulation of the polyurethane foam walls was tested by placing a digital temperature and humidity sensor inside the chamber for a period of $24 \mathrm{~h}$. The humidity was temporarily increased by filling up the bottom of the chamber with a layer of expanded clay aggregate, which was soaked and sprayed with water prior to being placed in the device. The conditions inside the chamber were proven to be stable and maintained for prolonged periods of time without unexpected rapid temperature or humidity changes.

All of the selected solutions make the chamber very easy to assemble but also sturdy, rigid, and able to provide a considerable level of thermal and moisture insulation in order to provide the ability to maintain relatively stable conditions inside the device (Figure 5), with the intention to reduce the overall power consumption during the operation of the device (maintaining more stable conditions within the chamber and shielding its interior from the external elements reduces the amount of runtime the sub-systems need to adjust for the fluctuations).

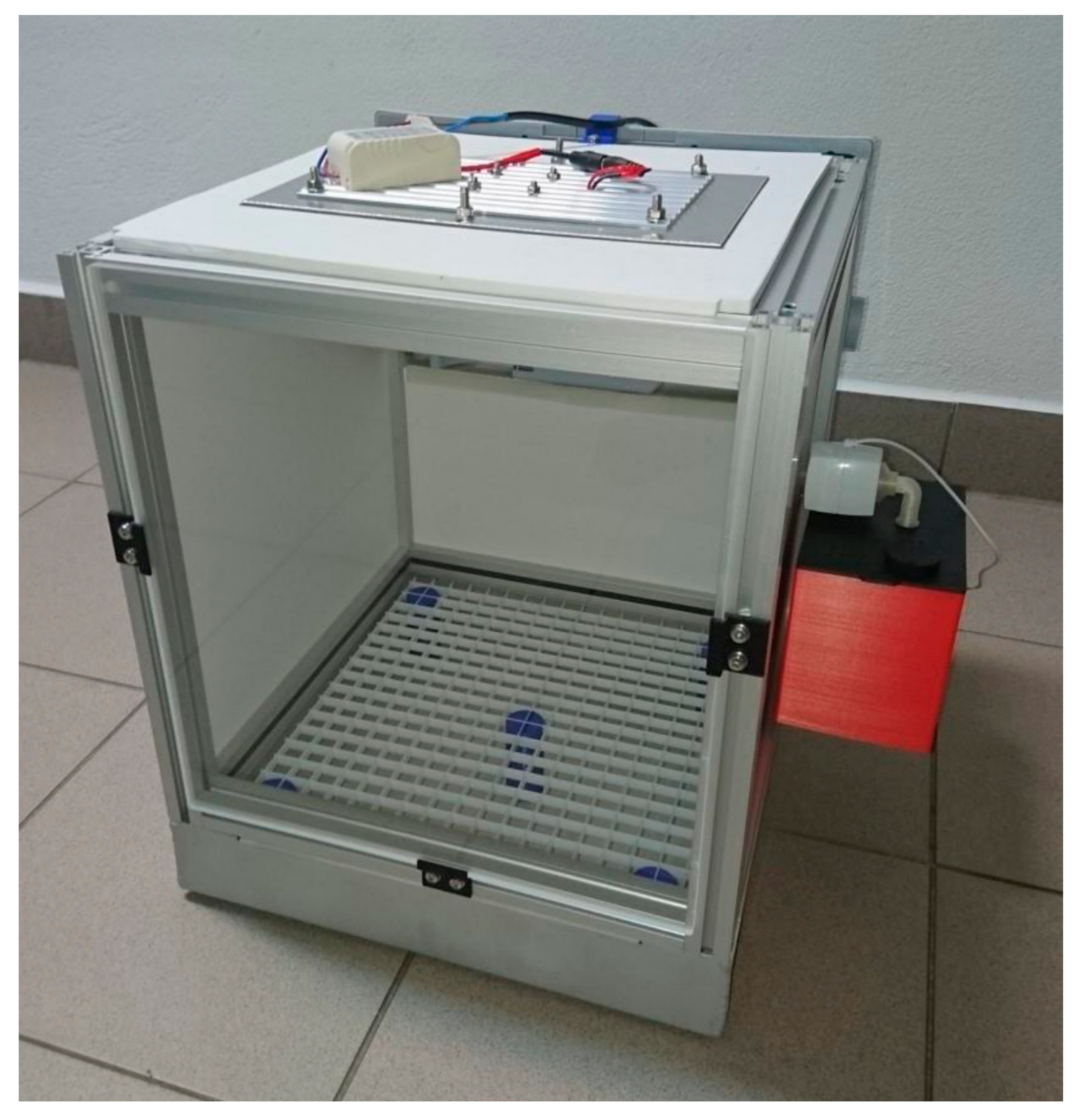

Figure 5. Fully assembled environmental chamber.

\section{Characteristics of the Sub-Systems}

Depending on the requirements, environmental chambers vary in size, level of insulation provided, internal equipment, and, of course, price. In this project, the authors focused on a design aimed especially at providing conditions sufficient for cultivating plant species native to the Guiana Highlands. They originate from locations characterized by very peculiar environments, such as highland cloud forests and misty mountain tops with notably high levels of sunlight exposure or rocky highland riversides. To achieve this, during the designing process not only the technical aspect of the project needed to be taken into consideration but also some botanical knowledge and first-hand horticultural experience, which lets one understand the principles of plant cultivation and the environmental specification of their natural habitats.

The prototype is based on a modular design. Should the project scope change, the chamber can be easily adapted to new requirements by exchanging or just re-fitting individual modules. In addition 
to various chamber sizes, it is possible to modify light sources and its intensity, airflow direction, temperature range, and the internal maximum growspace. This flexible design allows the chamber to be modified for different applications, resulting in a more "future-proof" device.

A scheme of the complete device is presented below (Figure 6).

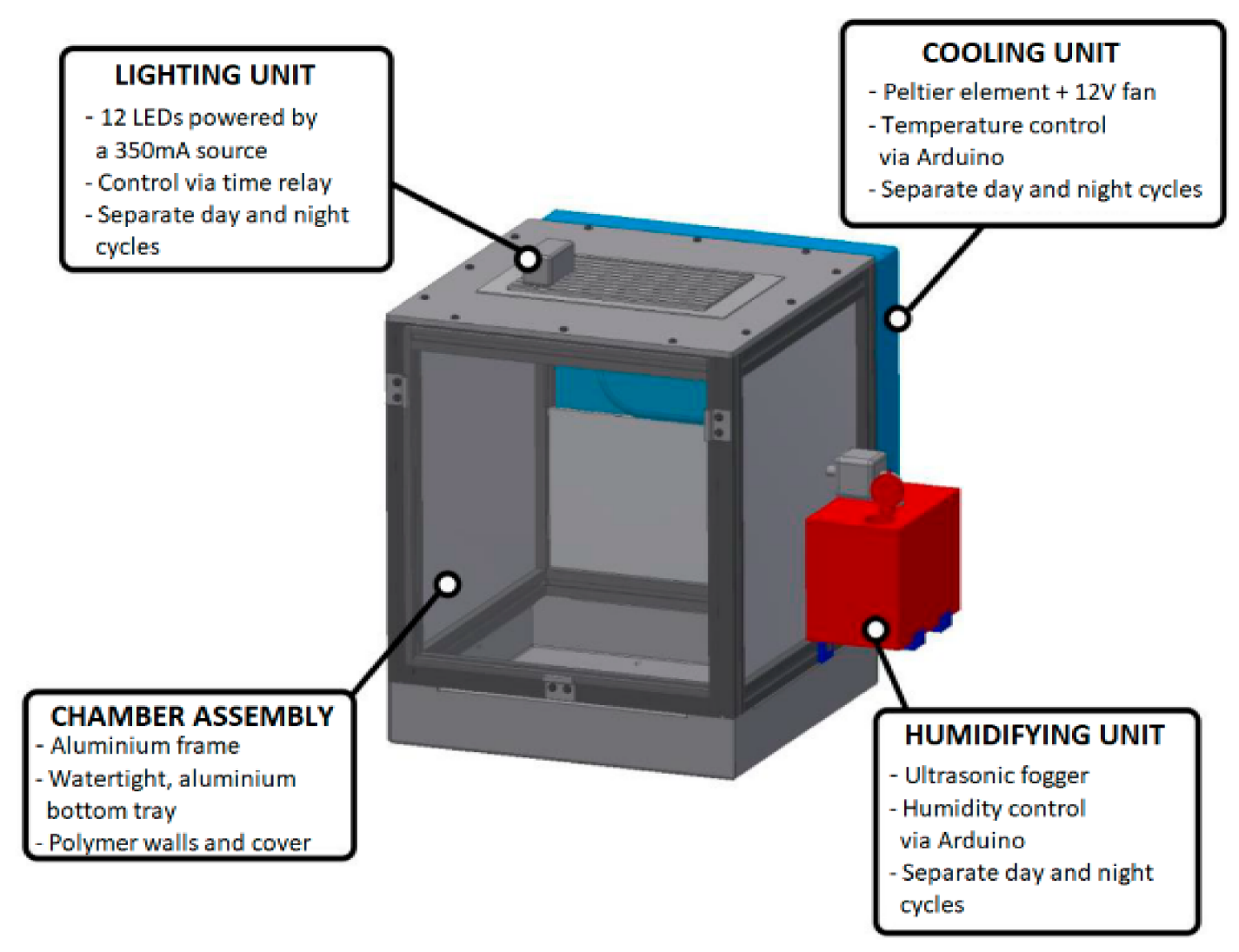

Figure 6. Scheme presenting the main features of the device.

Before starting the design process, one must confront his ideas with ground assumptions and a theoretical basis. In order to provide appropriate conditions for the test subjects (plants) to be grown inside the chamber, the following parameter values were taken as the desired ones to be re-created inside the device:

- Lighting period-12 h per day (typical period for subequatorial areas, like the Canaima National Park in Venezuela;

- Temperature range-most inferences of meteorological data from Pantepui have been based on the altitudinal range of the tepui summits. The lower summits, situated between 1500 and $2400 \mathrm{~m}$ elevation, have annual average temperatures reaching up to approximately $18^{\circ} \mathrm{C}$ [15] with significant daytime/nighttime differences depending on the exact altitude or levels of direct sun exposure. To provide more flexibility, the chamber must provide conditions matching the requirements of some species occurring also at lower altitudes, where the climate is much milder. Approximations were also applied to accommodate for the hardware limitations arising from the low-cost nature of the design. Therefore, averaged values were taken as the basis and present as follows:

- $\quad 23^{\circ} \mathrm{C}-27^{\circ} \mathrm{C}$ (during the lighting period-daytime simulation);

- $\quad 19^{\circ} \mathrm{C}-23^{\circ} \mathrm{C}$ (during the nighttime); and

- humidity range- $-75-100 \%$. 
The assumptions were based on empirical observations that were made by the first author in Venezuela and supplemented with practical horticultural knowledge on the environmental requirements of selected plant species.

\subsection{Cooling Unit}

The cooling unit providing the temperature drops required to grow tropical highland plant species is a simple setup based on the so-called Peltier effect module. Its cooling capabilities originate from a combination of the Peltier effect, Joule effect, and heat conduction [16]. A thermoelectric effect is the direct conversion of temperature differences to electric voltage and vice versa. A Peltier module consists of two ceramic plates separated from each other by a group of semi-conductive elements. When the electric current is supplied, the temperature on one of the ceramic plates increases, while that on the other one decreases.

The Peltier module TEC-12706 used in this project, according to the producer, has a maximum power of $34 \mathrm{~W}$ and is run with an external power supply providing a $12 \mathrm{~V}$ DC current (Figure 7). Operating this device with such a kind of current reduces the overall performance, but on the other hand, it results in better operational stability and much safer operation. The power supply chosen to run the cooler is a $48 \mathrm{~W} 12 \mathrm{~V}$ unit to assure an additional power safety margin. The cooling device selected for this project was a double-radiator cooler with a Styrofoam insulation, adjusted in a way to enable direct installation onto the main chassis of the chamber, which was achieved using specially designed 3-D-printed parts.

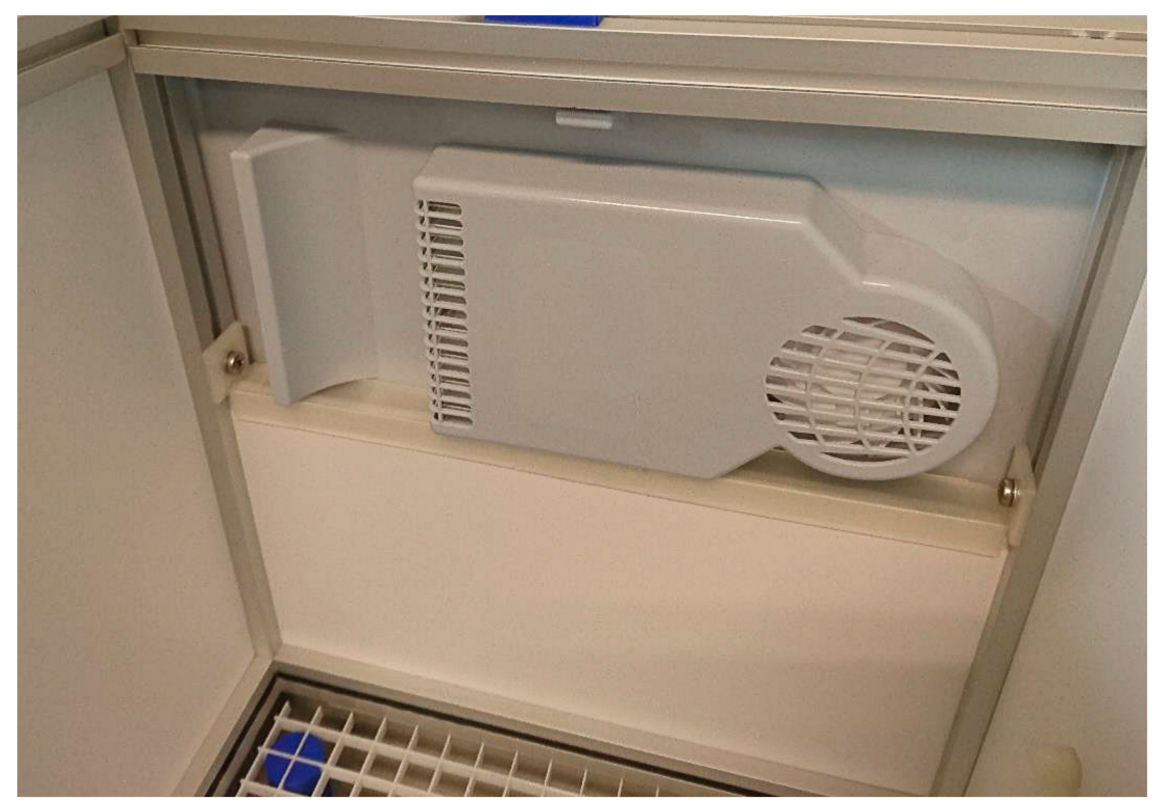

Figure 7. Peltier module-based cooling system installed in the chamber.

\subsection{Lighting Unit}

The lighting unit is a simple LED lamp designed and assembled in a way to provide the proper lightwave spectrum for plant growth. Light wave-lengths matching exactly the vegetational needs of the plants have two main "peaks", as shown in the graph below (Figure 8) [17]. Thanks to the use of LEDs, one is able to obtain significant levels of energy efficiency compared to other means of illuminating the plants (like high-pressure sodium lamps). With the use of LEDs, it is not necessary to waste energy on wavelengths the plants do not require in their life processes, as light-emitting diodes are capable of delivering a stable source of light characterized by one specific wavelength [18]. LED setups are also much safer to use than the "classic" horticultural solutions (fluorescent tubes, 
high-pressure sodium lamps etc.), as they usually operate on lower currents and do not bear certain environmental risks as the ones typical for other light sources (like the fluorescent tubes).

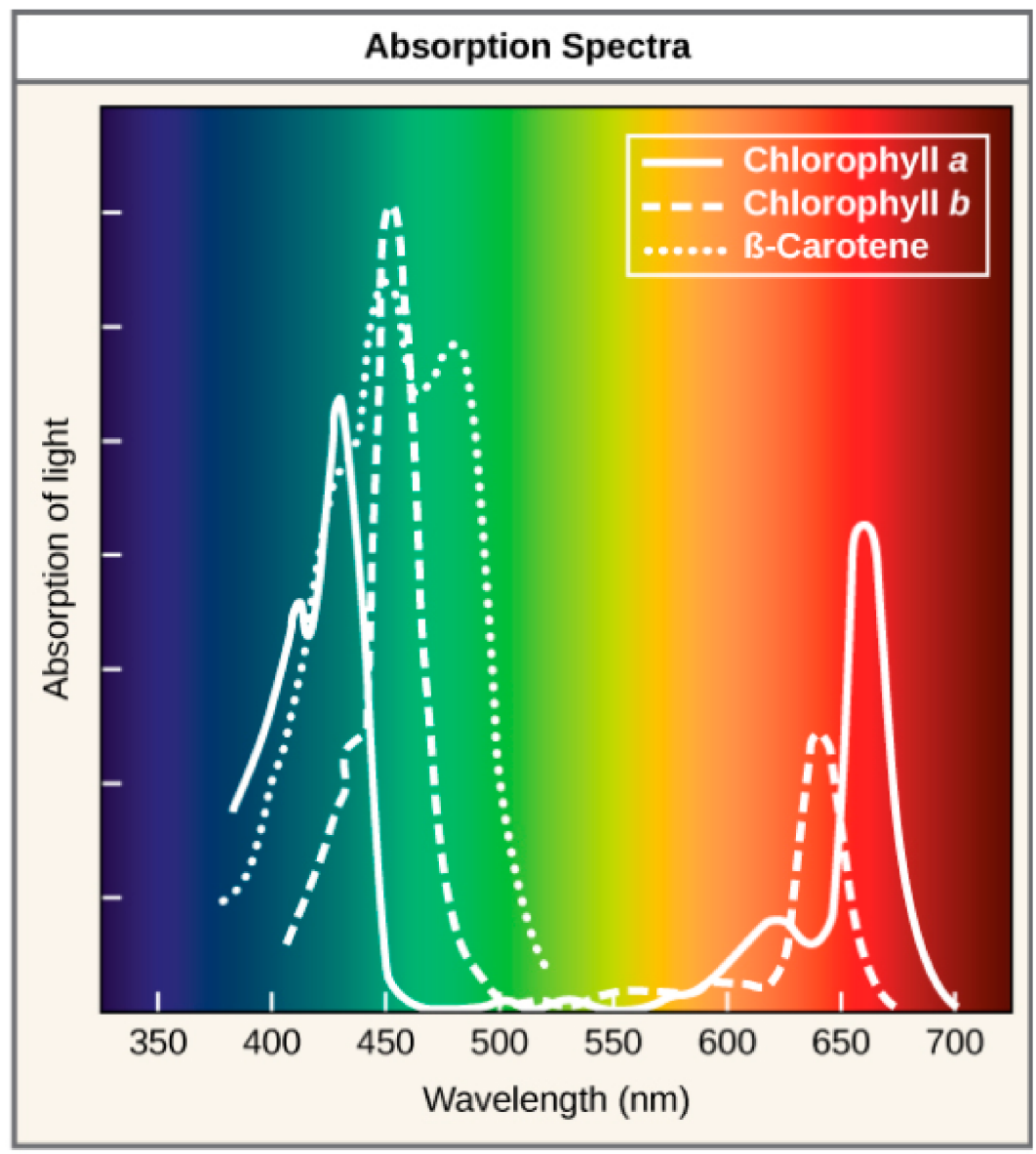

Figure 8. Light energy absorption in green plant tissues (for chlorophyll A—blue line and B-green line) in relation to light wavelengths [17]. From The Light-Dependent Reactions of Photosynthesis. In Biology 2e, by OpenStax: Houston, Texas, USA, 2018.

The diodes used for this project were constant $350 \mathrm{~mA}$ current-operated LEDs in the total number of 12 mounted onto a printed circuit board (PCB) and a radiator, helping to dissipate the excess heat (Figure 9). All the electrical components were soldered together, and thermoconductive glue was added for better heat dissipation.

The power supply is a constant-current $350 \mathrm{~mA}$ unit screwed onto the radiator on the top of the chamber. The following set of diodes was used:

- $\quad 2 \times$ Deep Red (660 nm) diodes;

- $2 \times$ Royal Blue (440 nm) diodes;

- $2 \times$ "Multi-spectrum" diodes; and

- $6 \times$ Cool White $(6500 \mathrm{~K})$ diodes.

The main easily understandable principle is that the deep red wavelength boosts the generative growth of the plants, while the royal blue wavelength induces vegetative growth [19]. The cool white diodes were added mainly for aesthetic reasons; the chamber is supposed to be placed in a publicly visible spot, so it is important to make the light output as aesthetically pleasing as possible.

The assembly of the unit was simple and straightforward. After purchasing all items required, the diodes were soldered onto the specially prepared spots on the aluminum PCB plate. A small amount of thermal paste was applied on each diode to ensure more efficient heat dissipation. An aluminum 
radiator was glued and screwed onto the top of the PCB plate to further increase the cooling efficiency. The $350 \mathrm{~mA}$ power supply was connected to the diodes using a special jack-type plug, making it possible to easily cut the power off in case of any unexpected failures during the operation of the chamber.

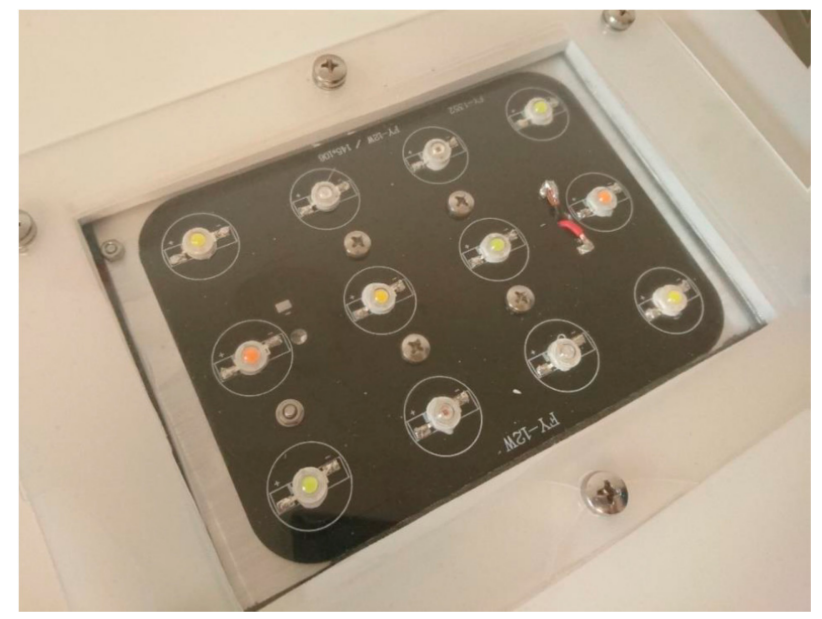

Figure 9. Lighting unit bottom side - LEDs soldered onto a PCB (printed circuit board) plate.

\subsection{Humidifying Unit}

The air humidifier is a special unit based on the use of an ultrasonic membrane with a microporous surface. The microscopic pores provide a constant transfer of the water from one side of the membrane to another. The ultrasonic vibrations that are generated when supplying the unit with electrical power disperse the water transitioning through the membrane, turning it into the form of a fine mist.

Devices responsible for performing such tasks as increasing the air humidity cannot operate without a proper way of storing the water volume: a reservoir. The first step in designing a humidifying unit was in effect finding the best and most reliable way to keep the water stored. After an unsuccessful market research, the option chosen was to design and make a reservoir. The final choice was a compact plastic design printed in a 3-D additive technology, providing a compact size, ease of use, and low production costs. Anchor points were made to mount the reservoir onto the side of the main aluminum frame (Figure 10).

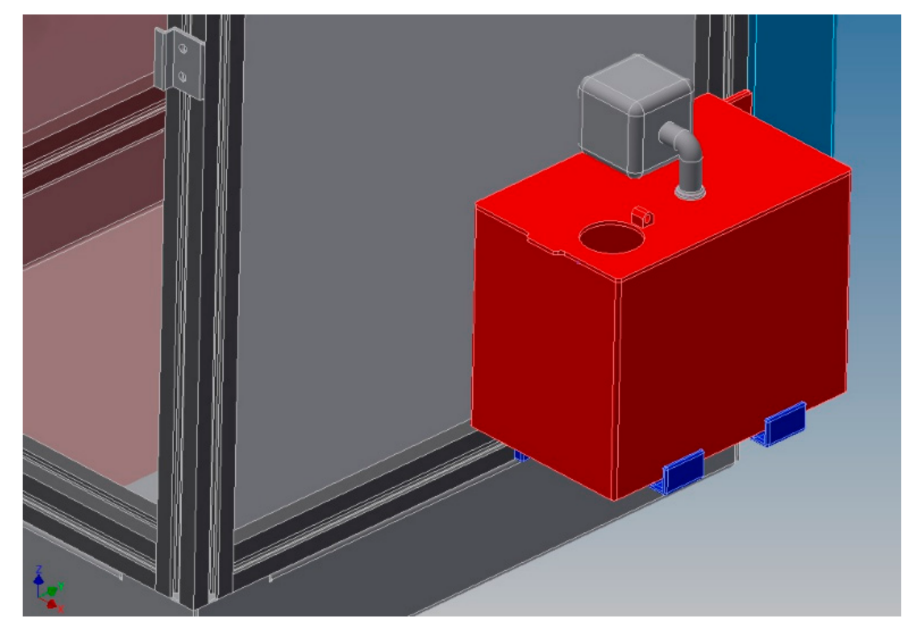

Figure 10. Humidifying unit 3-D CAD model.

The material chosen for the task was ABS (Acrylonitrile Butadiene Styrene), a very popular and cheap yet reliable material for the FDM 3-D printing technology. Later, a microporous membrane-based electrical unit was added, connected to the reservoir via 3-D-printed tubes and joints. 
The unit is being run by a $5 \mathrm{~V}$ current and is connected to an external power supply. It is mounted onto a 3-D-printed box-like structure acting as a reservoir capable of holding about $1 \mathrm{~L}$ of water. Specially designed tubes and threaded connectors provide direct access into the interior of the chamber. The reservoir is covered by a layer of ABS plastic. In the reservoir cover, there is a small opening with a hinged lid through which one is able to refill the tank.

\section{Overview of the Digital Control System}

After completing the assembly process of the chamber, the next step was to equip the device along all the sub-systems with a suitable digital control unit.

Some of the most essential variables in the growspace environment that affect the development of the plant life are temperature, relative humidity, light, and in more professional applications also $\mathrm{CO}_{2}$, nutrient solutions, $\mathrm{pH}$, or the electrical conductivity within the soil and water. A good understanding of each control parameter and their interactions with other variables of the system, such as the growspace structure and covering materials, instrumentation properties, and requirements of the plants in different growing stages, need to be studied in order to design a proper control algorithm that is able to correlate with the input (energy load), and output (enhanced quality) [20].

The market of open-source electronic control systems is constantly growing. Ready-to-use solutions available on the market are often very expensive, and their possibilities of being implemented in such a device as an environmental chamber are very limited. In order to have the best possible flexibility during the design process, the most cost-effective and convenient decision is to rely on solutions based on widely popular open-source software with a good knowledge base available on the internet. This way, the engineer is not limited to using high-grade expensive systems aimed at a limited group of professional customers, such as scientists or academic employees.

After market research, the system that was chosen by the authors was the Arduino system based on the Arduino Uno motherboard. This system has a very large and active followers community online, which results in the knowledge base being easily reachable; therefore, all required troubleshooting was much easier in comparison to other solutions that could have been implemented [21]. On the prototype level of development of the device, Arduino Uno was assessed as being sufficient to perform the tasks required by the project.

Arduino/Genuino Uno is a microcontroller board based on the AT-mega328P. It has 14 digital input/output pins (of which 6 can be used as PWM outputs), 6 analog inputs, a $16 \mathrm{MHz}$ quartz crystal, a USB connection, a power jack, an ICSP header, and a reset button. It contains everything needed to support the microcontroller within itself. The Arduino kit has a wide range of sensors and extra add-ons that can be implemented, so it would allow further development of the project in the future, including new control systems or ideas, without the need to change the control systems completely. The elaborated system is programmable in a coding language similar to the " $\mathrm{C}$ " environment.

In order to have control over all the desired parameters in the chamber, it was necessary to purchase proper modules and accessories in order to expand the stock capabilities of the Arduino Uno motherboard. The full list of hardware used is listed below:

- HD44780 LCD display;

- Buttons (4 pcs.);

- DHT22 temperature and humidity sensor;

- RTC DS3231 real time clock module;

- 10 A 2-relay modules (2 pcs.);

- Prototyping breadboard;

- Cables and wires; and

- $\quad$ Power supply.

The home screen visible right after switching the device $\mathrm{ON}$ is the real-time reading of temperature $\left({ }^{\circ} \mathrm{C}\right)$ and humidity levels (\%) within the chamber, provided by the DHT22 sensor. The default time 
interval of data collection is one minute and can be adjusted after implementing changes in the source code.

A detailed description of the user interface and control layout of the chamber's sub-systems is presented in Appendix A (Appendix A.1).

\subsection{Cooling Unit Control}

The cooling unit is engaged or disengaged depending on the current setting of a 10 A relay, which is controlled by the DHT22 thermometer. The sensor collects temperature data with an interval of $5 \mathrm{~s}$ and is capable of obtaining reads with an accuracy of $0.1^{\circ} \mathrm{C}$. When the temperature level exceeds the desired value, the control system sends a signal to the relay, which engages the Peltier cooling unit. It stays engaged until the moment the sensor reads the temperature corresponding to the minimal value set in the program. If the value drops below a certain level, the relay changes its setting and breaks the electrical circuit, cutting off the power supply of the cooling unit.

The DHT22 sensor provides constant checking of the current temperature values. The principles of the cooling system's operation are very simple: the device is engaged when the sensor registers a temperature exceeding the maximum value set in the beginning, and disengages when the minimal defined value is reached.

The Peltier cooling device is equipped with two aluminum radiators (one dissipates the heat generated on the "hot plate", which enables the Peltier thermoelectric effect to start, cooling down the "cold plate") and two fans responsible for providing sufficient heat dispersion. The fan installed inside the environmental chamber not only helps to spread the chilled air around the chamber's interior but also provides an imitation of cold mountain wind, which mimics the conditions from the tepui tabletop mountains.

The operation algorithm is presented in a flow chart below (Figure 11).

\subsection{Lighting Period Control}

Control of the lighting systems varies significantly from the ones used for maintaining the desired temperature and humidity levels. In this case, no specific value is being measured with the use of sensor units, but it is required to control the relay module with a preset value of time. Achieving this requires the use of one more extra module: a real-time clock (RTC DS3231). It is equipped with a CR2032 battery providing time and date data storage capabilities when the device is not plugged into the main power source. An example of the lighting period setting user interface is presented in Figure 12 below.

\subsection{Humidifying Unit Control}

The principle of the humidity control operation is similar to the operation of the cooling system. The only difference is that the value measured by the DHT22 sensor is not temperature but air humidity.

The sensor collects humidity reads with an interval of $5 \mathrm{~s}$ and is capable of obtaining reads with an accuracy of $0.1 \%$. When the humidity drops below the desired value, the control system sends a signal to the relay, which engages the humidifier unit. It remains enabled until reaching a humidity level corresponding to the maximum value set in the program. If the value rises above a certain level, the relay switches and breaks the electrical circuit, disabling the humidifier.

The operation principle is presented in a flow chart below (Figure 13). 


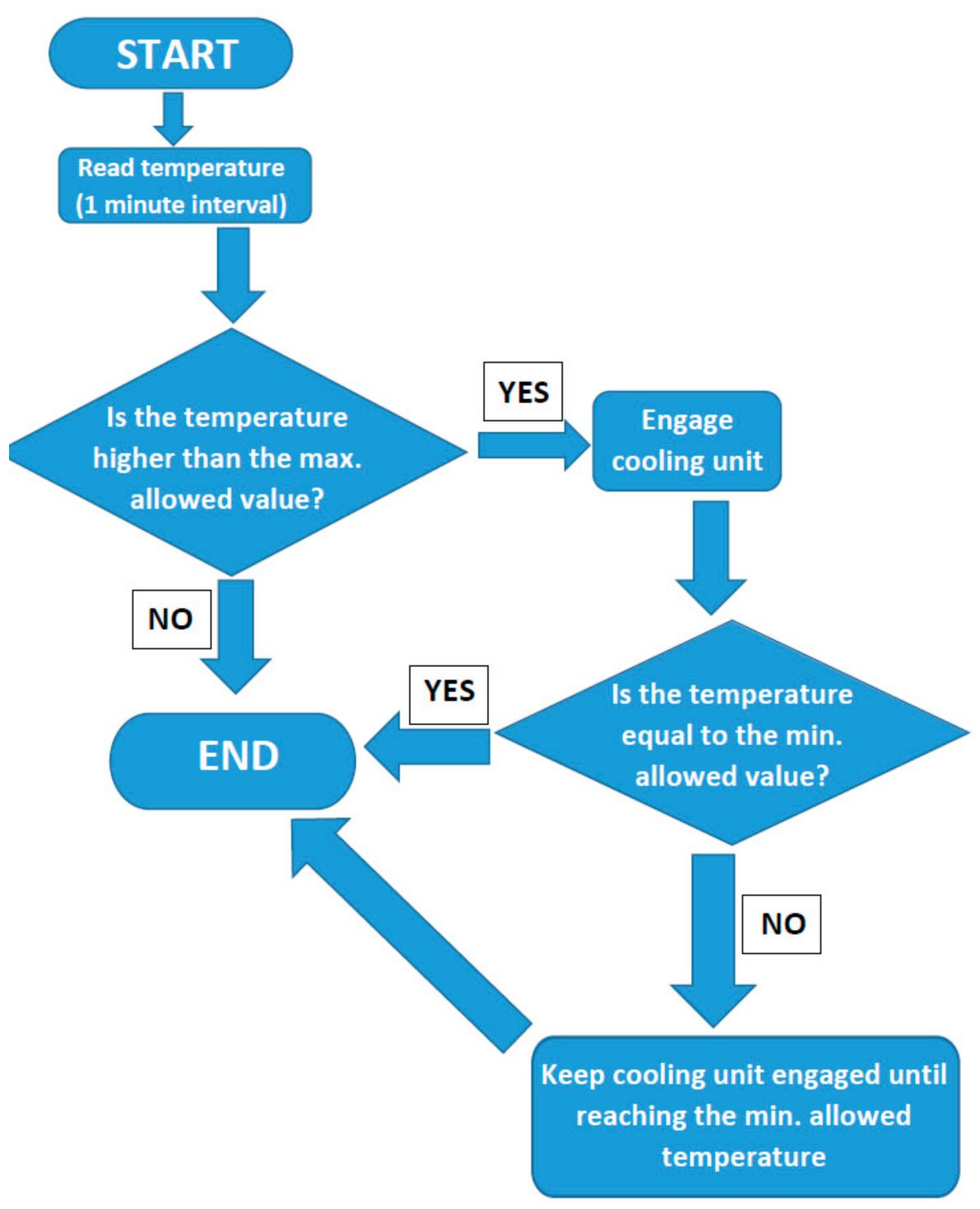

Figure 11. Structure of the temperature control algorithm.

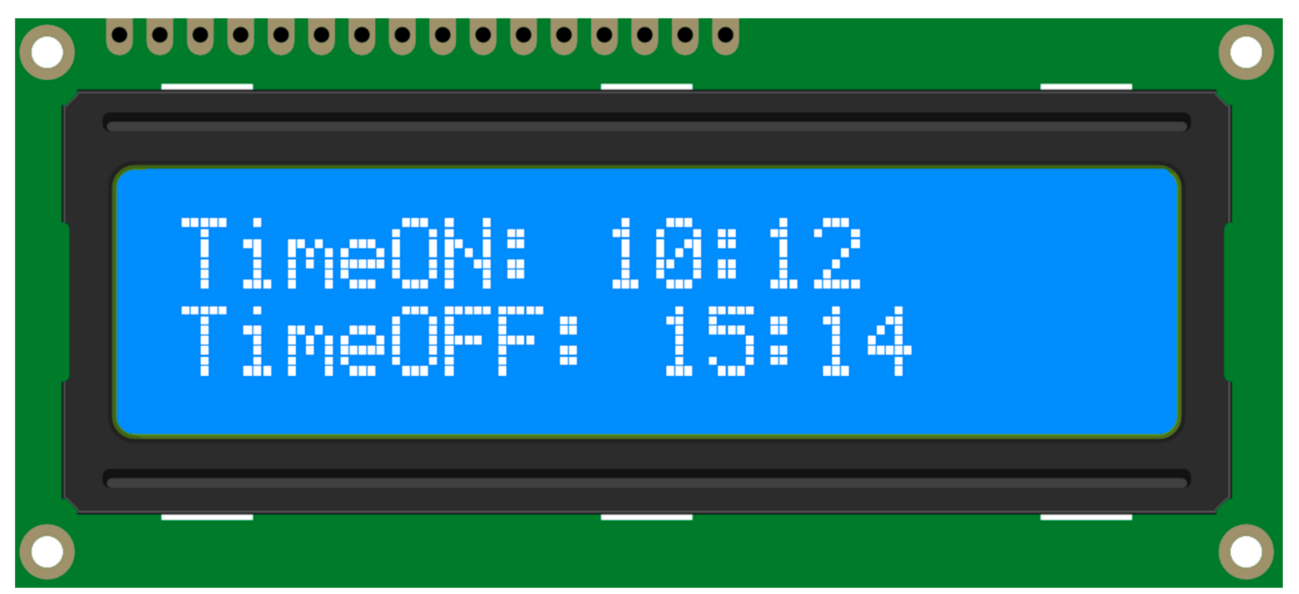

Figure 12. Exemplary screen of the lighting period control interface. 


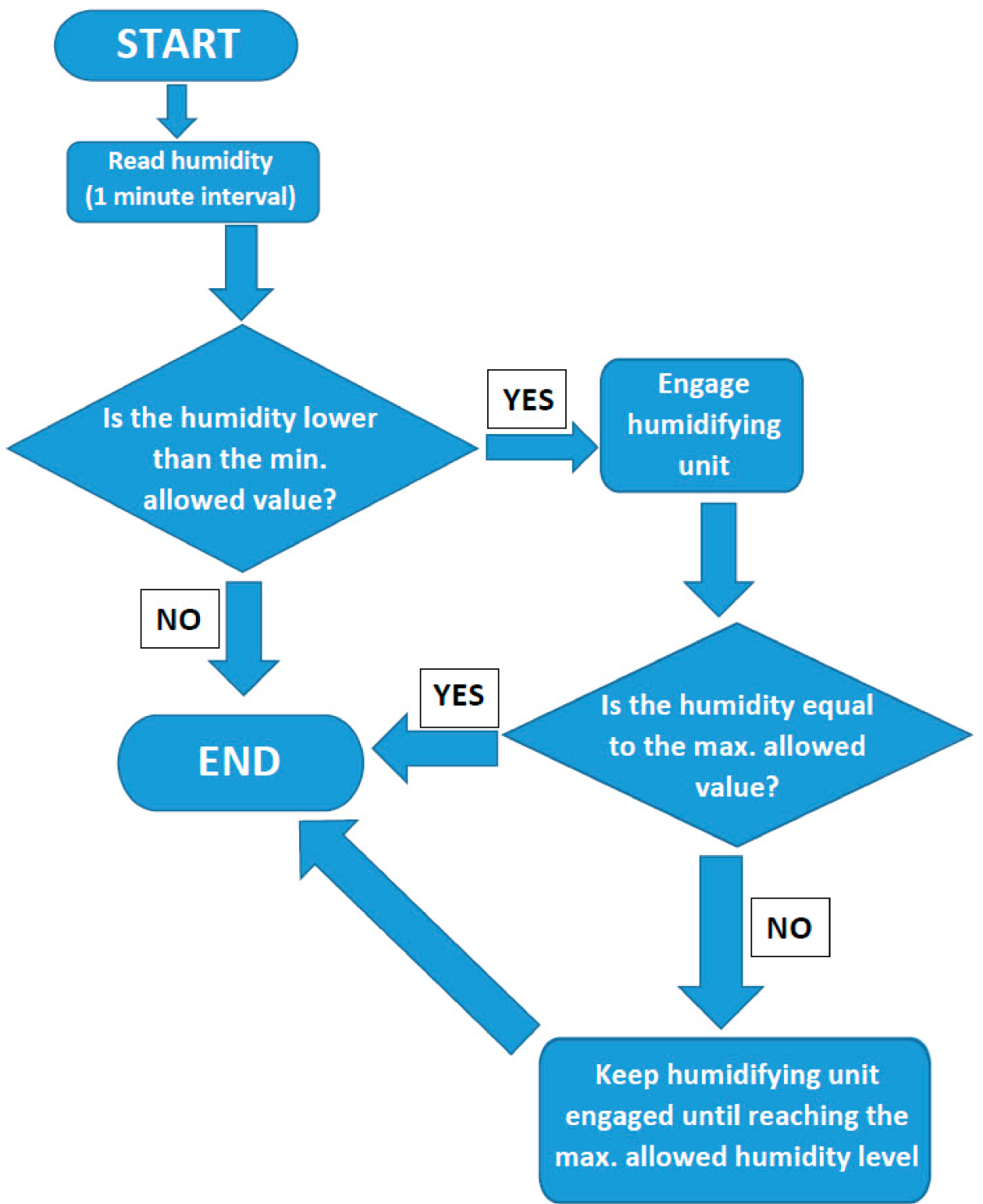

Figure 13. Structure of the humidity control algorithm.

\section{Results of Test Runs and Operation of the Chamber}

After completing the assembly of the chamber and programming for the control system, the device was put under testing. The main tests included:

- Checking the operation of the cooling unit;

- Checking the operation of the humidifying unit; and

- Checking the operation of the time relay switch of the lighting unit.

All of the tests were planned and carried out separately in order to achieve the most accurate and unbiased results.

In the beginning, the cooling unit was prepared for being initially checked. The goal of the first test was to assess the capability of the unit to perform the operation of decreasing the temperature inside the chamber, so a simple test run was performed in enclosed conditions in order to see whether a temperature drop occurs when the unit is activated. The chamber was assembled, cleaned, and sealed to prevent the ambient air from entering into the chamber. The test was carried out in an ambient temperature of $26.4^{\circ} \mathrm{C}$, and all measurements were taken in series with a 20-s interval. The minimal 
value defined in the control system settings was $10{ }^{\circ} \mathrm{C}$ (the minimal possible value). The results obtained are shown in a graph below (Figure 14).

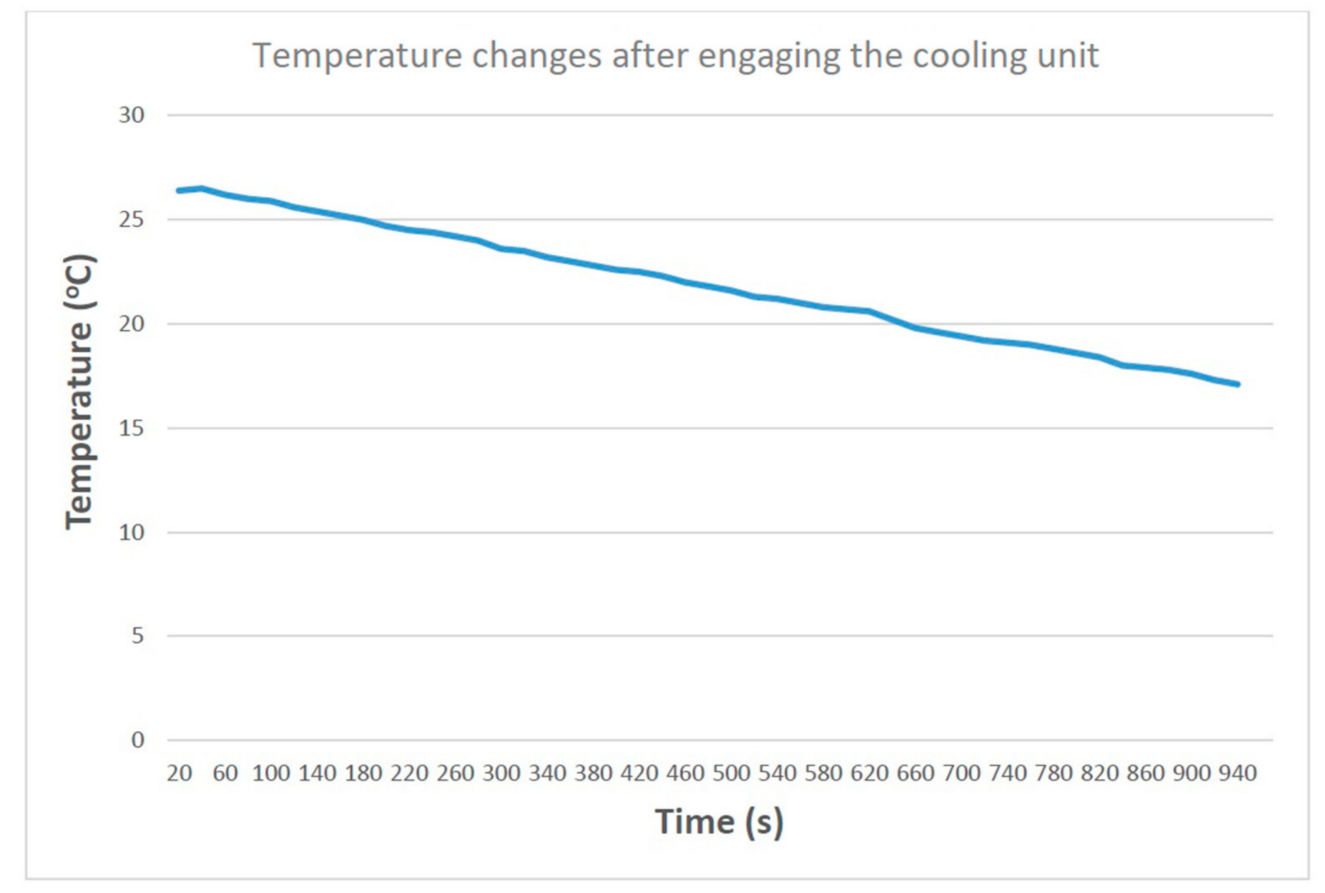

Figure 14. Plot presenting the results of the cooling system's test run.

The minimal recorded value was $17.1{ }^{\circ} \mathrm{C}$ and was achieved after $15 \mathrm{~min}$ and $40 \mathrm{~s}$ from the start of the experiment. The minimal temperature achieved was $9.3^{\circ} \mathrm{C}$ lower than the ambient temperature. The LED lamp causes the temperature inside the chamber to rise when engaged, to an extent dependable on the ambient humidity; with an ambient air humidity of $55 \%$, the temperature rises to approximately $30^{\circ} \mathrm{C}$, so the conclusion is that it is possible to achieve almost a $13^{\circ} \mathrm{C}$ temperature drop after disengaging the lighting unit, which would normally be done during the night time. The values achieved are sufficient for the horticultural requirements defined in Section 4, which was concluded based on the first author's past practical experiences regarding the environmental tolerance of selected plants in cultivation. The aim was to achieve a daytime temperature of less than $30^{\circ} \mathrm{C}$ with a night drop in order to mimic cool nights in the highland wetland habitats. The test results prove that such a performance is achievable in the device considering suitable ambient conditions.

The next step was to test the operation of the lighting unit: an LED lamp installed on the top of the chamber, acting also as a top cover of the device. The lamp was connected to the relay module in the control system, then it was set to engage at 12:00 and disengage at 12:30. The test was successful, as the relay module operated flawlessly without causing any problems or errors in other sub-systems.

The last thing checked was the operation of the humidifying unit, with an emphasis put on its relay module. The humidity level typically occurring in the tepui highland wetland habitats fluctuates between $70 \%$ and $95 \%$. After placing the sensor in a relatively dry environment for the testing (ambient humidity below $60 \%$ ), the relay module proved to be working correctly, engaging and disengaging the fogging unit in accordance with the programmed rules. An additional test was undertaken to verify the temporal efficiency of the unit. The chamber was dried using a portion of silica gel desiccant to obtain a starting humidity level of $20 \%$ before engaging the humidifying unit. The test was then carried out in an ambient temperature of $26.4{ }^{\circ} \mathrm{C}$ (the same as the cooling unit test), and all measurements taken in series with a 1-s interval. The results obtained are shown in a graph below (Figure 15). 


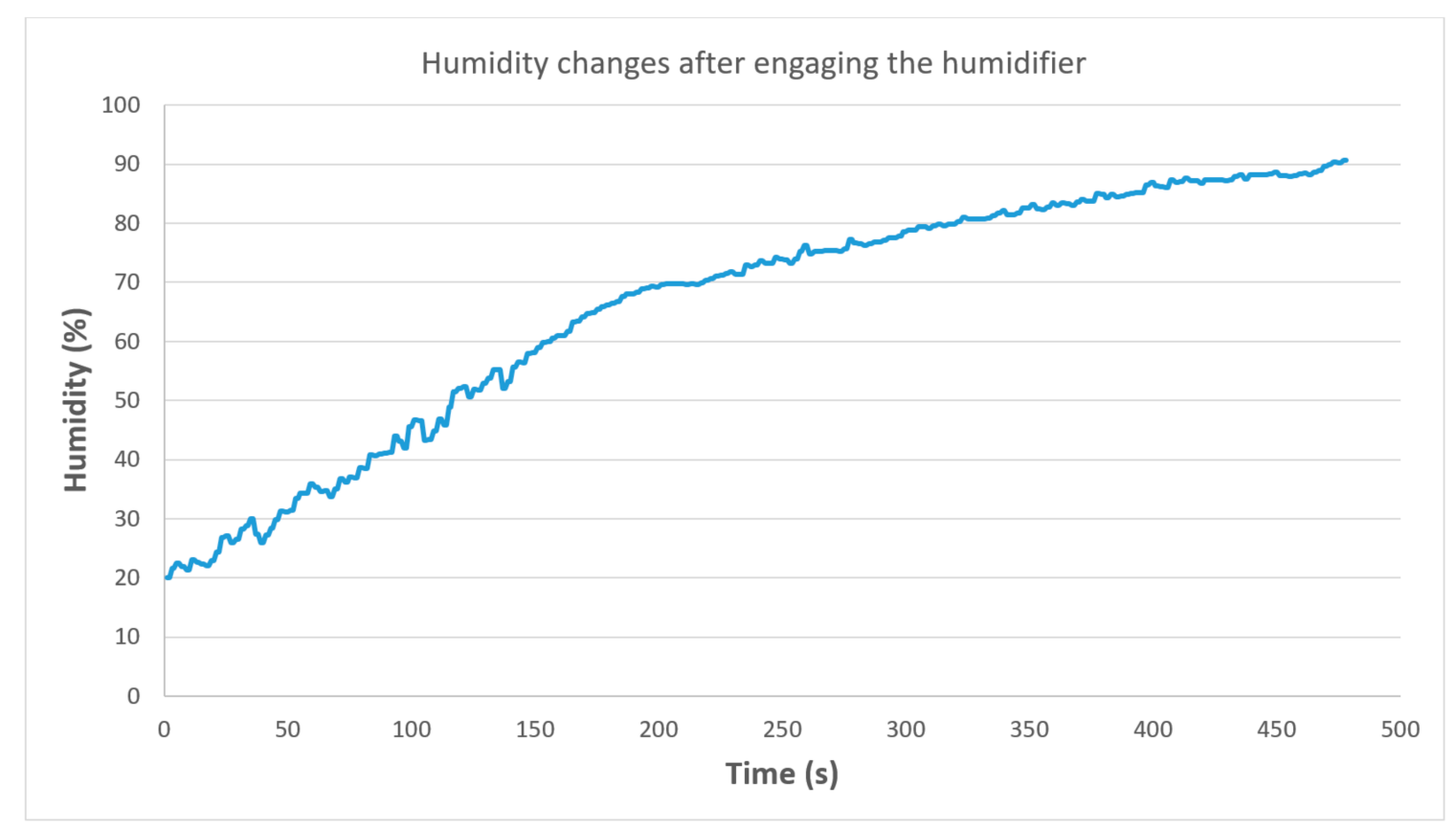

Figure 15. Plot presenting the results of the humidifying unit's test run.

The maximal recorded value was $90.6 \%$ and was achieved after $7 \mathrm{~min}$ and $58 \mathrm{~s}$ from the start of the test.

In order to ensure that the chamber was operating in a satisfying manner, a 24-h-long test was carried out, simulating the complete daytime and nighttime cycles. The control system was set with values corresponding to the initial assumptions mentioned in the beginning of the paper, whereas the ambient temperature was kept at the level of $26^{\circ} \mathrm{C}$. The values set are presented in Table 1 below.

Table 1. Values set for the chamber test runs.

\begin{tabular}{ccc}
\hline & Daytime (6:00-18:00), Light ON & Nighttime (18:00-6:00), Light OFF \\
\hline Temperature & $\min .23^{\circ} \mathrm{C}, \max .27^{\circ} \mathrm{C}$ & $\min .19^{\circ} \mathrm{C}, \max .2{ }^{\circ} \mathrm{C}$ \\
\hline \multirow{2}{*}{ Humidity } & $\min .70 \%$, & $\min .70 \%$, \\
& $\max .100 \%$ & $\max .100 \%$ \\
\hline
\end{tabular}

The results of the test runs are presented as graphs in Appendices A.2 and A.3.

Both tests have proven the chamber's operation to match the base assumptions mentioned in the beginning of the paper.

\section{Real-life Practical Testing Results}

In order to determine whether the chamber is suitable for operating as a device aimed at the cultivation and propagation processes for the Guiana Highlands flora species, real-life tests were performed using living specimens obtained from professional plant nurseries. A batch of test specimens was selected to mimic a miniature habitat typical to the highland wetlands on Akopan-tepui and its mid-elevation surroundings in La Gran Sabana. The species selected included:

- Heliamphora pulchella (Sarraceniaceae);

- Heliamphora exappendiculata (Sarraceniaceae);

- Utricularia quelchii (Lentibulariaceae);

- Utricularia alpina (Lentibulariaceae);

- $\quad$ Stegolepis sp. (Rapateaceae); 
- $\quad$ Orectanthe sceptrum (Xyridaceae);

- Maguireothamnus speciosus (Rubiaceae);

- Paepalanthus sp. (Eriocaulaceae);

- Brocchinia reducta (Bromeliaceae);

- Drosera arenicola (Droseraceae);

- Drosera roraimae (Droseraceae); and

- Cyrilla racemiflora (Cyrillaceae).

These species occur commonly on Akopan-tepui and its mid-elevation vicinities, often growing together in patches of peat bogs.

The specimens were planted in a medium comprised of peat, dried Sphagnum sp. moss, and fine-grain quarzitic sand and placed inside the chamber for a period of 4 months. The control unit setpoint values were the same as in the test runs (Appendix A.2 Appendix A.3). Plants were monitored to maintain adequate soil moisture levels, with water applied on the soil by hand every other day. Due to the lack of access to water from the natural habitats in South America, it was decided to simplify the test by using distilled water as a nutritiously neutral and widely available cost-effective solution for watering the plants. The choice was based on the first author's practical horticultural experiences with using distilled water for cultivating fragile tropical plants as a mean of avoiding unwanted sediments or mineral inclusions in the soil, which often jeopardize the cultivation efforts by damaging the plants or inhibiting their growing processes.

The growth of the plants was monitored and compared to similar specimens kept in a traditional glass vivarium equipped with no automatic systems. All environmental particulars in the vivarium were adjusted by hand using manual tools (water sprayers, electric switches) and a simple electronic time relay to enable rudimentary control over the lighting unit (a fluorescent tube setup).

The results of the tests ended with all plant specimens having not only survived but showing no visible negative health symptoms during the time being placed inside the chamber and relying in many ways on its systems to perform their life processes (Figure 16). Specimens of Drosera arenicola, Paepalanthus sp., Utricularia alpina, and Heliamphora pulchella successfully went through their blooming cycles while being placed inside the chamber, which might be an indicator of the LED setup being designed adequately to support generative growth. A comparison of the results and observations is presented in Table 2 below.

Table 2. Observation results: growing plants in an automated chamber compared to specimens kept in a manually maintained glass vivarium.

\begin{tabular}{cc}
\hline $\begin{array}{c}\text { Automated } \\
\text { Environmental } \\
\text { Chamber }\end{array}$ & $\begin{array}{c}\text { Traditional } \\
\text { Glass } \\
\text { Vivarium }\end{array}$ \\
\hline $\begin{array}{c}\text { LED unit generating less heat than a fluorescent } \\
\text { tube, resulting in more stable conditions inside } \\
\text { the chamber }\end{array}$ & $\begin{array}{c}\text { Fluorescent lighting unit causing excess rise in temperature } \\
\text { and humidity drops, resulting in occasional burns of the } \\
\text { upper parts of the plants }\end{array}$ \\
\hline $\begin{array}{c}\text { Air humidity maintained by an } \\
\text { automated system }\end{array}$ & Manual spraying - uneven distribution of water mist \\
$\begin{array}{c}\text { Automatic, ventilated cooling system providing } \\
\text { an imitation of wind and temperature drops } \\
\text { at night }\end{array}$ & $\begin{array}{c}\text { Temperature changes and airflow dependent on ambient } \\
\text { conditions, increasing the risk of fungal infections and } \\
\text { resulting in notably diminished growth of highland and } \\
\text { montane plants during exceedingly warm periods, as well } \\
\text { as reduced coloration of the leaves }\end{array}$ \\
\hline $\begin{array}{c}\text { Constant control over temperature and } \\
\text { humidity levels. Convenient operation } \\
\text { and adjustments }\end{array}$ & $\begin{array}{c}\text { Conditions adjusted manually resulting in occasional } \\
\text { overheating, droughts and other problems caused by } \\
\text { human errors }\end{array}$ \\
\hline
\end{tabular}




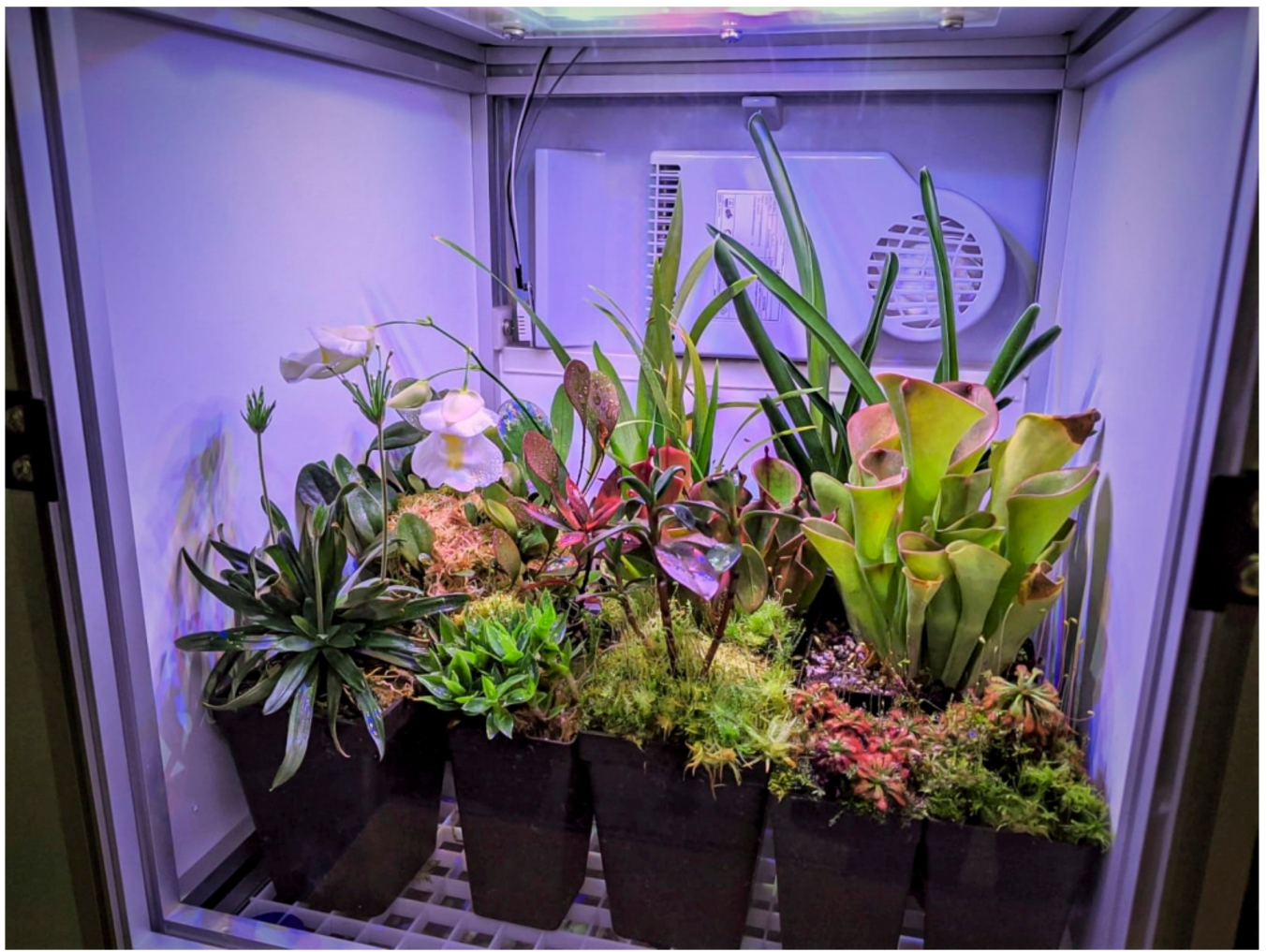

Figure 16. Plants growing in the chamber. Note the presence of inflorescence on Utricularia alpina and Paepalanthus sp. specimens.

It is important to mention that due to the fact that the subject of this project is primarily of an engineering nature, botanical experimentation was largely simplified and limited to external observations on the condition of the plant specimens grown inside the chamber.

\section{Discussion}

Although the operation of the environmental chamber showed potential for satisfying operation in small-scale horticultural use despite its limitations, one must never stop thinking about the possibilities for further development. The market for digitally controlled compact terrariums or fitotrons is currently very limited in scale, so the topic can unfold a notable potential for future applications when developed further, finding recipients both in science and industry, as well as among biology enthusiasts, tropical plant collectors, and plant nurseries.

The test runs revealed that the humidifying unit was the most problematic one amongst all of the sub-systems. It is necessary to come up with ideas for a more efficient and powerful unit for the sake of future development of the device.

In order to make the device applicable for commercial use, it might be necessary to design much larger chambers capable of housing a wider variety of plant specimens. A larger device would require the use of much more capable and powerful sub-systems, resulting in the need to implement major changes in the overall design.

A very interesting idea worth mentioning in terms of future development plans is the implementation of functions based on the use of the so-called fuzzy logic. The theory is connected with the theory of fuzzy sets. In fuzzy logic, between state 0 (false) and state 1 (true), a series of intermediate values extend that determine the degree of belonging of an element to the set. It is commonly employed to handle the concept of partial truth, where the truth value may range between completely true and completely false [22,23]. The general architecture of a fuzzy logic structure is shown in a graph below (Figure 17). 


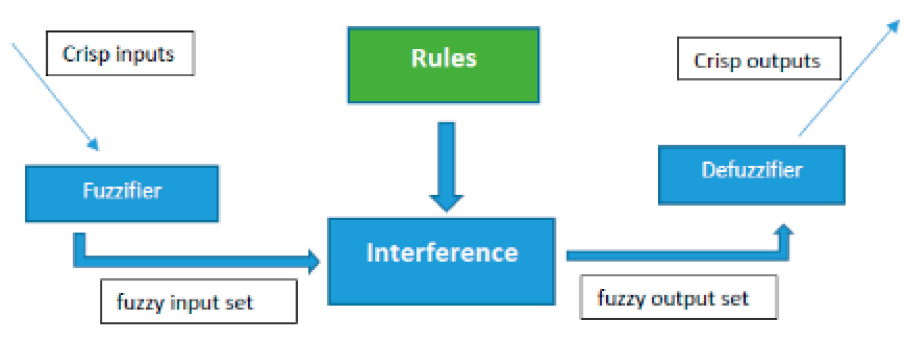

Figure 17. Example of a fuzzy logic system.

A good example of a function based on the fuzzy logic principles, with a possible application being the future versions of the environmental chamber control system, would be a cooling unit controlled by a fuzzy logic algorithm. Such a system would adjust the temperature inside the chamber according to the momentary temperature inside the chamber and a target value. Such a temperature control system would be different than the one proposed in this project, as it would operate not on the actual numerical values but more on specifically defined linguistic variables. Of course, the idea of controlling the temperature with the use of fuzzy logic is just one of many possible examples for future implementation in the design.

Additional sub-systems can be added to allow control over more environmental particulars or to refine the systems currently implemented. The cooling unit based on the use of the Peltier module is efficient only for very small chambers, such as the one presented in this paper. In order to make the temperature control system more practical, it would be necessary to install other solutions capable of both reducing and raising the temperature inside the device. Expanding the unit with a simple heater would vastly improve the overall flexibility of the system, enabling full control over the temperature changes, as in the current design only the LED lamp doubles to some extent as a warming unit during the daytime operation. An auxiliary set of fans should be installed to increase the airflow, thus resulting in higher efficiency of the mountain wind simulation.

For larger chambers, an example of an efficient way of cooling is by using systems based on compressor water chillers equipped with a set of pumps and radiators, circulating the water through a heat exchanger placed inside the growspace. An operation scheme for such a system is presented in the form of simple graphs showing the cooling medium circulation (Figure 18). Such a system could be made even more flexible by supplementing the cooling unit with electrics, allowing the operator to both increase and decrease the temperature.

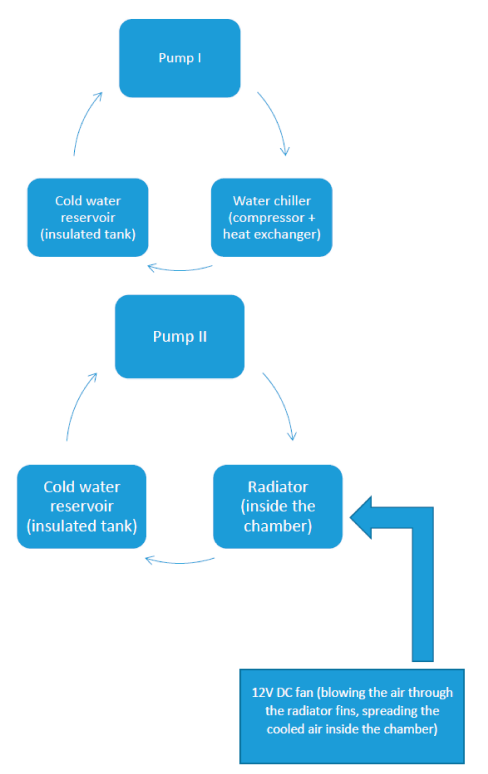

Figure 18. Graph presenting the circulation of the cooling media inside a temperature control system based on a compressor water chiller. 
The last thing to consider is the digital control system. With the currently available solutions, the possibilities for development seem to be almost unlimited. It is possible to implement more sensors and relay modules in order to take control over more sub-systems, as well as expand the capabilities of the currently installed ones, such as the LED lamp. For example, the source code can be changed to accommodate control over multiple different lighting periods. With the implementation of professional, accurate sensors, it will also be possible to use the device in more advanced scientific projects requiring precise control over the environmental conditions.

A more thorough review and tests on living plant specimens grown inside the chamber must be undertaken to assess whether the device can be used for more professional horticultural projects. More detailed botanical experiments will be required to study the actual condition of the test specimens.

It is necessary to take into consideration the main issues influencing the final form of the project one desires to develop: the actual market demands and the pricing range of the final product. Assembling a system based on more sophisticated technical solutions requires a significantly higher amount of funds and meticulous quality control throughout the production process, if one wishes to make the device commercially available.

\section{Conclusions}

Despite all the flaws and problems mentioned above, the authors confirm, on the basis of the conclusions drawn from several tests completed, that the horticultural chamber prototype provides an acceptable performance level to find use in amateur (sub)tropical horticulture applications. It is necessary, though, to acknowledge certain limitations given by the simplistic design and low-cost approach of this project. In order to provide more advanced automation solutions for horticultural processes similar to the ones presented in this paper, it is required to research more sophisticated means of environmental control and sensor systems. The device developed for the needs of this project covers only the most basic plant growing requirements, so the eventual success in the cultivation process of certain species remains dependent on external factors and challenges that need to be solved with the use of other means, most likely manually. These factors include tasks, such as applying adequate growing media (soil) and maintaining correct acidity and moisture levels, pest monitoring, fertilizing, and others. The designed chamber in its current shape is a simple and affordaale solution for amateur users mostly, in which role it performs by providing sufficient results.

Author Contributions: conceptualization, M.W. and A.B.; methodology, M.W. and A.B.; validation, A.B.; formal analysis, A.B.; investigation, M.W.; resources, M.W.; writing- original draft preparation, M.W.; writing-review and editing, A.B.; visualization, M.W.; supervision, A.B. All authors have read and agreed to the published version of the manuscript.

Funding: This research received no external funding.

Acknowledgments: Wojciech Moczulski is thanked for his co-supervision over the project. Stewart McPherson is thanked for organizing the expedition in Venezuela in January 2017. Antonio Hitcher, Javier Mesa and members of the community of Yunek in Estado Bolivar, Venezuela are thanked for providing logistics and guidance during the expedition to Akopan-tepui. Andy Smith, Michael Schach and Andreas Wistuba are thanked for their help obtaining living plant material. Michał Kapuściński is thanked for the help with code writing \& assembly of the electronic components.

Conflicts of Interest: The authors declare no conflict of interest.

\section{Appendix A}

Appendix A.1. Description of the User Interface and Control Layout of the Chamber's Sub-Systems

Appendix A.1.1. Main Menu

The home screen of the user interface is the current reading of temperature $\left({ }^{\circ} \mathrm{C}\right)$ and humidity levels (\%) within the chamber, provided by the DHT22 sensor. The time interval of data acquisition is 
one minute and can be adjusted after implementing changes in the source code. The control system has a very basic and user-friendly interface consisting of an LCD screen and 4 buttons:

- SELECT;

- UP;

- DOWN; and

- $\quad$ BACK.

The user is able to enter the sub-menus and adjust all desired control values by pressing the SELECT button while seeing the home screen. Pressing the BACK button causes a return to the home screen regardless of the screen that is currently being showed on the display.

\section{Appendix A.1.2. Temperature Control Unit Setting}

In order to set the temperature range, the user needs to push the SELECT button and using the UP/DOWN buttons find a "Set temp range" screen, and then push SELECT again to enter the value adjustment menus. The minimal possible temperature is $10^{\circ} \mathrm{C}$ while the maximum is $45^{\circ} \mathrm{C}$. After adjusting all settings and saving each of them with the SELECT button, final confirmation screens are displayed, showing the new range of parameter values the chamber will be operating with and a "TEMP SET" screen in the end. After displaying the confirmation for $3 \mathrm{~s}$, the home screen appears automatically. The logic system has a fail-safe software lock preventing the input of incorrect values, that is, for example, when the chosen minimum temperature is higher than the maximum, and vice versa.

\section{Appendix A.1.3. Lighting Unit Setting}

In order to set the lighting period after setting the current time and date with the help of the real time clock module, the user needs to push the SELECT button and use the UP/DOWN buttons find a "Set Lux range" screen, and then push SELECT again to enter the value adjustment menus. The following screens will be displayed consecutively:

- Time $\mathrm{MMON}$-for adjusting the minute value of the ON time;

- Time $\mathrm{HH} O \mathrm{ON}$-for adjusting the hour value of the ON time;

- $\quad$ Time MM OFF-for adjusting the minute value of the OFF time; and

- $\quad$ Time $\mathrm{HH}$ ON—for adjusting the hour value of the OFF time.

After adjusting all settings and saving each of them with the SELECT button, final confirmation screens are displayed, showing the new times of engaging and disengaging the LED lamp on a daily basis and a "LIGHT TIME SET" screen in the end. After displaying the confirmation for $3 \mathrm{~s}$, the home screen appears automatically.

\section{Appendix A.1.4. Humidifying Unit Setting}

In order to set the humidity range, the user needs to push a SELECT button and use the UP/DOWN buttons find a "Set Hum range" screen, and then push SELECT again to enter the value adjustment menus. The minimal possible humidity is $10 \%$, while the maximum is $95 \%$. After adjusting all settings and saving each of them with the SELECT button, final confirmation screens are displayed, showing the new range of values the chamber will be operating with and a "HUMIDITY SET" screen in the end. After displaying the confirmation for $3 \mathrm{~s}$, the home screen appears automatically. 
Appendix A.2. Graph: Test Results of a 12-Hour-Long Daytime Simulation in the Chamber

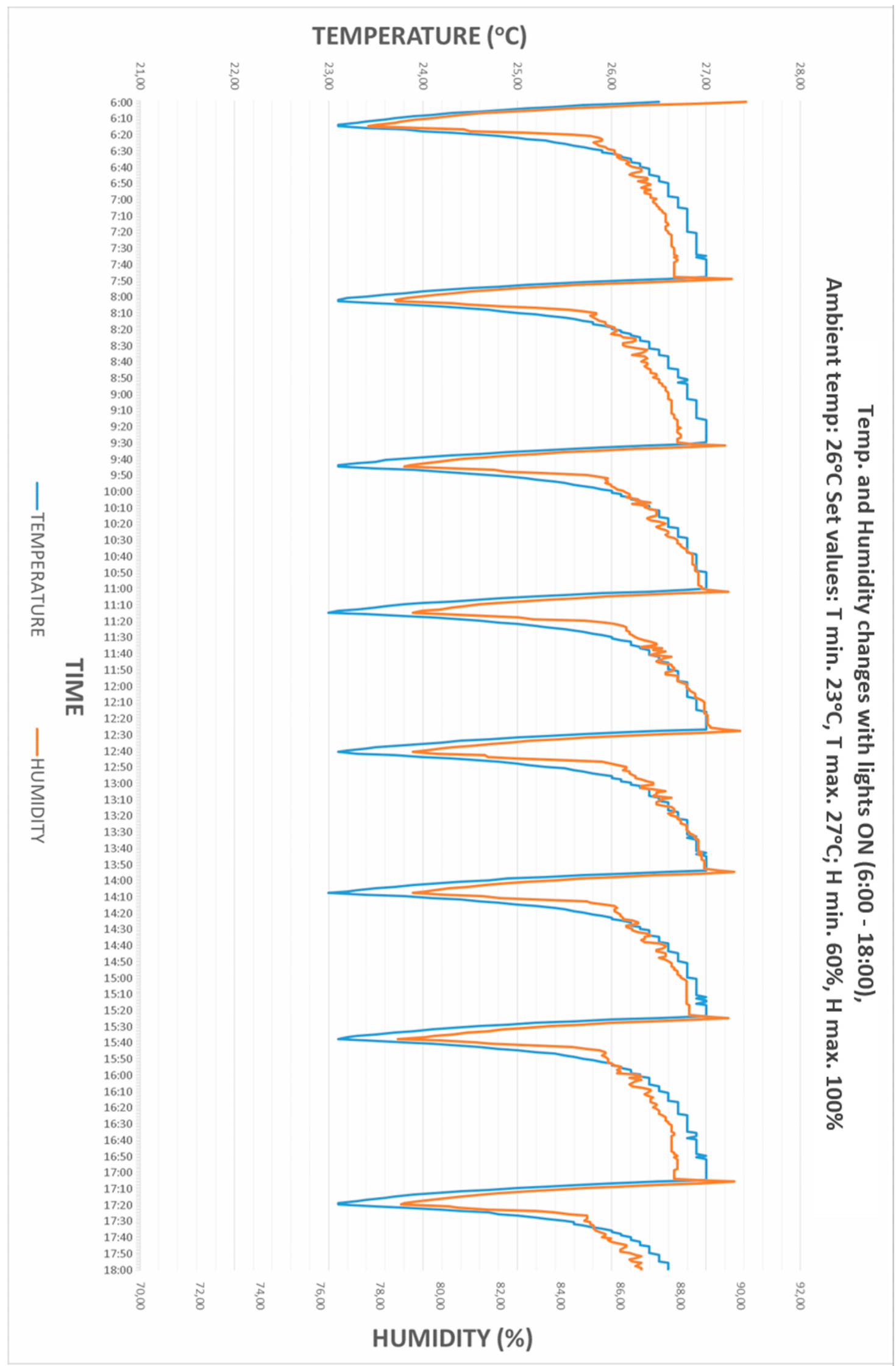


Appendix A.3. Graph: Test Results of a 12-Hour-Long Nighttime Simulation in the Chamber

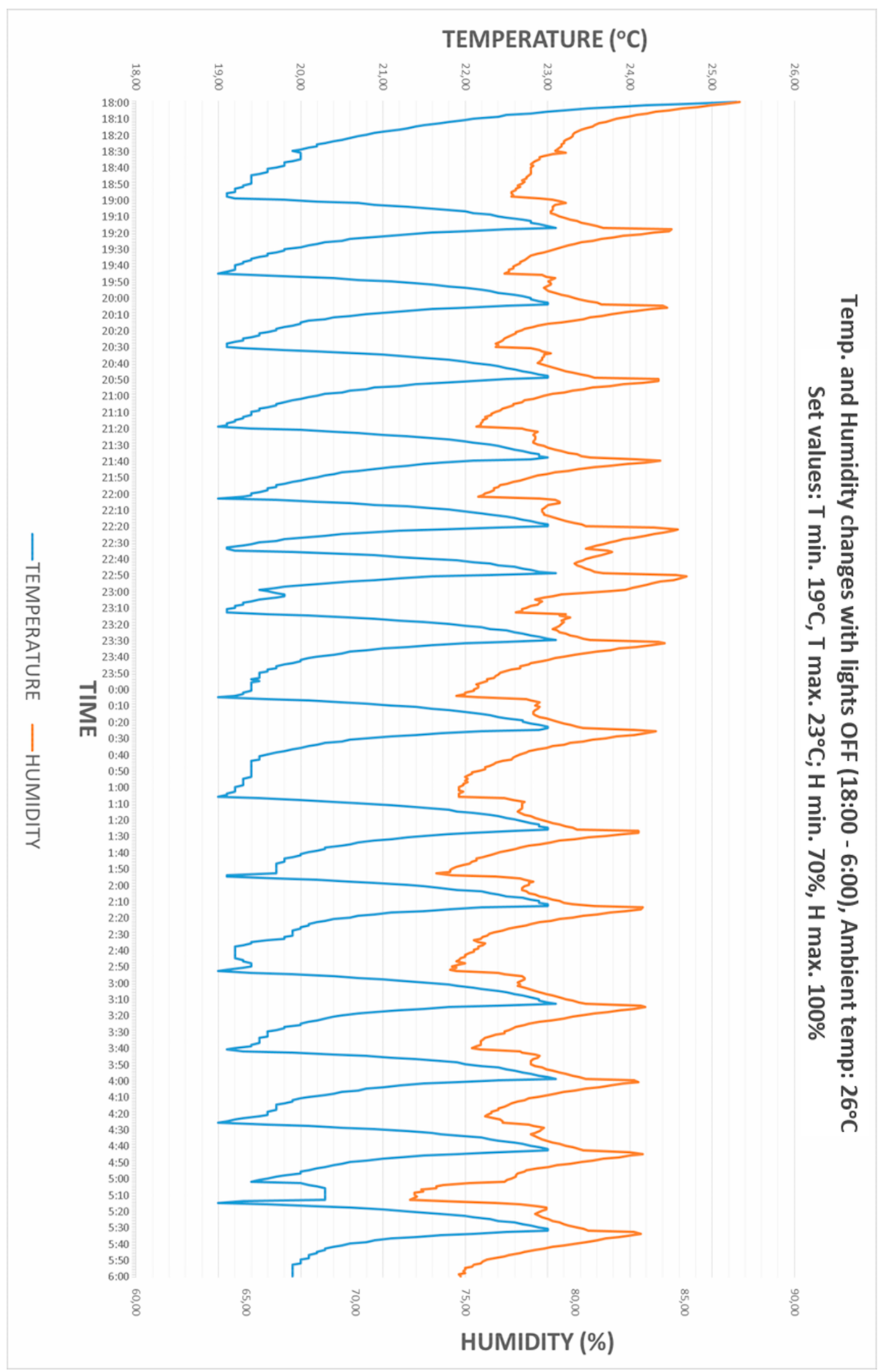




\section{References}

1. Hook, M.; Mayer, M. Miniature environmental chambers for temperature humidity bias testing of microelectronics. Rev. Sci. Instrum. 2017, 88, 034707. [CrossRef] [PubMed]

2. Totani, C.M.; Stiffey, A.V. Construction of an Environment Chamber. Bios 1979, 50, 106-110.

3. Schwantes, R.H.; McVay, R.C.; Zhang, X.; Coggon, M.M.; Lignell, H.; Flagan, R.C.; Wennberg, P.O.; Seinfeld, J.H. Chapter 1: Science of the Environmental Chamber. In Advances in Atmospheric Chemistry; Barker, J.R., Steiner, A.L., Wallington, T.J., Eds.; World Scientific Publishing Co. Pte. Ltd.: Singapore, 2017.

4. Ramachandran, A.V.; Nazarious, M.I.; Mathanlal, T.; Zorzano, M.P.; Martín-Torres, J. Space Environmental Chamber for Planetary Studies. Sensors 2020, 20, 3996.

5. Katagiri, F.; Canelon-Suarez, D.; Griffin, K.; Petersen, J.; Meyer, R.K.; Siegle, M.; Mase, K. Design and Construction of an Inexpensive Homemade Plant Growth Chamber. PLoS ONE 2015, 10, e0126826. [CrossRef] [PubMed]

6. Cantley, R.; Clarke, C.M.; Cokendolpher, J.; Rice, B.; Wistuba, A. Nepenthes clipeata Survival Project. Carniv. Plant Newsl. 2005, 34, 116-120.

7. McPherson, S.; Wistuba, A.; Fleischmann, A.; Nerz, J. Sarraceniaceae of South America; Redfern Natural History Productions Ltd.: Dorset, UK, 2011.

8. McPherson, S. Lost Worlds of the Guiana Highlands; Redfern Natural History Productions Ltd.: Dorset, UK, 2008.

9. Brewer-Carias, C. Roraima, the Crystal Mountain (English ed.); Arte Press: Caracas, Venezuela, 1978.

10. D'Amato, P. The Savage Garden: Cultivating Carnivorous Plants; Ten Speed Press: New York, NY, USA, 2013.

11. Michelangeli, F.A. Species composition and species-area relationships in vegetation isolates on the summit of a sandstone mountain in southern Venezuela. J. Trop. Ecol. 2000, 16, 69-82. [CrossRef]

12. Vegas-Vilarrúbia, T.; Nogué, S.; Rull, V. Global warming, habitat shifts and potential refugia for biodiversity conservation in the neotropical Guayana Highlands. Biol. Conserv. 2012, 152, 159-168. [CrossRef]

13. Rull, V.; Nogué, S.; Safont, E.; Vegas-Vilarrúbia, T. Pantepui and global warming. In Biodiversity of Pantepui; Elsevier BV: Amsterdam, The Netherlands, 2019; pp. 403-417.

14. Safont, E.; Vegas-Vilarrúbia, T.; Rull, V. Use of Environmental Impact Assessment (EIA) tools to set priorities and optimize strategies in biodiversity conservation. Biol. Conserv. 2012, 149, 113-121. [CrossRef]

15. Huber, O. Geographical and physical features. In Flora of the Venezuelan Guayana, Vol. 1: Introduction; Berry, P., Holst, B.K., Yaskievych, K., Eds.; Missouri Botanical Garden Press: St. Louis, MO, USA, 1995; pp. 1-61.

16. Gillott, M.; Jiang, L.; Riffat, S. An investigation of thermoelectric cooling devices for small-scale space conditioning applications in buildings. Int. J. Energy Res. 2009, 34, 776-786. [CrossRef]

17. Clark, M.A.; Douglas, M.; Choi, J. The Light-Dependent Reactions of Photosynthesis. In Biology 2e; OpenStax: Houston, TX, USA, 2018.

18. Hitz, T.; Henke, M.; Graeff-Hönninger, S.; Munz, S. Three-dimensional simulation of light spectrum and intensity within an LED growth chamber. Comput. Electron. Agric. 2019, 156, 540-548. [CrossRef]

19. Massa, G.D.; Kim, H.-H.; Wheeler, R.M.; Mitchell, C.A. Plant Productivity in Response to LED Lighting. HortScience 2008, 43, 1951-1956. [CrossRef]

20. Shamshiri, R. A Review of Greenhouse Climate Control and Automation Systems in Tropical Regions. J. Agric. Sci. Appl. 2013, 2, 175-182. [CrossRef]

21. Ali, A.S.; Zanzinger, Z.; DeBose, D.; Stephens, B. Open Source Building Science Sensors (OSBSS): A low-cost Arduino-based platform for long-term indoor environmental data collection. Build. Environ. 2016, 100, 114-126. [CrossRef]

22. Isik, C. Fuzzy Logic: Principles, Applications and Perspectives. SAE Tech. Paper 1991, 100, 393-396. [CrossRef]

23. Ross, T.J. Fuzzy Logic with Engineering Applications, 4th ed.; Wiley: Hoboken, NJ, USA, 2010.

Publisher's Note: MDPI stays neutral with regard to jurisdictional claims in published maps and institutional affiliations. 